\title{
Row Column Height Progression Theory
}

\author{
Dr. Asad Reza \\ (Patna Medical College, India)
}

\begin{abstract}
We have observed numbers to progress in natural order. These numbers can be arranged in a sequence and a generalised equation can be given to predict further coming numbers. Their sum or differences can be obtained by using equations. Here, the numbers are arranged in order of columns, rows and heights as in an array and their general equations to determine their positions and other operations are given.
\end{abstract}

Key -words - Column, Frequency, Harmonic, Height, Period, Row

\section{Row Column and Height Progression}

Introduction: We have seen an array of numbers practically everywhere, especially in calendars. Numbers are arranged in increasing order and that makes a progression. The properties of this progression wherein natural numbers are arranged in a specific order of row, column and height is discussed in this paper.

\section{Column Progression(CP)}

Consider an array of numbers as such:

\section{Increasing columns}

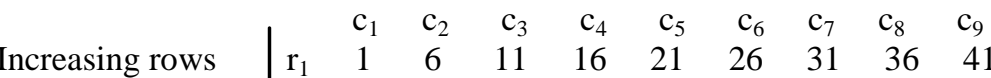

$\begin{array}{llllllllllll}\mathrm{r}_{1} & 1 & 6 & 11 & 16 & 21 & 26 & 31 & 36 & 41 & . . & . . \\ \mathrm{r}_{2} & 2 & 7 & 12 & 17 & 22 & 27 & 32 & 37 & 42 & . . & . . \\ \mathrm{r}_{3} & 3 & 8 & 13 & 18 & 23 & 28 & 33 & 38 & 43 & . . & . . \\ \mathrm{r}_{4} & 4 & 9 & 14 & 19 & 24 & 29 & 34 & 39 & 44 & . . & . . \\ \mathrm{r}_{5} & 5 & 10 & 15 & 20 & 25 & 30 & 35 & 40 & 45 & . . & . .\end{array}$

We observe that the number of rows (r) increases progressively downwards to fixed maximum value of 5 . The number of columns (c) vary and do not have a fixed limit and may extend to infinity. This kind of progression is known as a fixed-row column progression or simply as Column Progression (CP), as it is the column that progresses onwards.

Now we will start with the simplest form of column progression wherein the first member of the $\mathrm{CP}$ is also the common difference(c.d.) between two successive members in the CP.

2.1. Let the total number of rows be " $n$ " for any fixed-row column progression, having a common difference "d" between any two successive elements. Suppose we have to find a number N in the 'r'th row and 'c'th column, then the equation for finding the number is :

$$
\mathrm{N}=\mathrm{n}(\mathrm{c}-1) \mathrm{d}+\mathrm{rd}
$$

2.2. Now again, in a column progression having ' $n$ ' fixed rows with common difference ' $d$ ' between any two successive elements, there is a number $\mathrm{N}$ whose row and column position in the $\mathrm{CP}$ is to be determined. Then the equation for obtaining the row (r) and column (c) is:

(a). column, $\quad \mathrm{c}=\left\lfloor\frac{N}{n d}\right\rfloor$, i.e. $[\mathrm{N} \leq \mathrm{ncd}<\mathrm{N}+\mathrm{nd}, \mathrm{c} \in \mathrm{I}]$

When $\mathrm{N}$ is not divisible by ' $\mathrm{nd}$ ', ' $c$ ' is the smallest integer such that

ncd $>\mathrm{N}$ (i)

When $\mathrm{N}$ is divisible by 'nd' then, $\quad \mathrm{c}=\mathrm{N} / \mathrm{nd}$

Combining equations (i) \& (ii), we get as; 'c' is the smallest integer for which:

ncd $\geq \mathrm{N}$------ (iii)

(b). row, $\quad r=N / d-(c-1) n$

where ' $c$ ' is the column as determined above.

\subsection{Addition of numbers in column progression}

(i). For two numbers $\mathrm{N}_{1}$ and $\mathrm{N}_{2}$ taken from the same $\mathrm{CP}$ having ' $\mathrm{n}$ ' fixed rows and common difference, 'd', let the row-column (RC) position of $\mathrm{N}_{1}$ be $\mathrm{r}_{1} \mathrm{c}_{1}$ and $\mathrm{N}_{2}$ be $\mathrm{r}_{2} \mathrm{c}_{2}$.

The sum of $\mathrm{N}_{1}$ and $\mathrm{N}_{2}$ gives a number $\mathrm{N}$ whose row (R) and column (C), $\mathrm{RC}$ can be determined as follows:

when, $\quad \mathrm{r}_{1}+\mathrm{r}_{2} \leq \mathrm{n}$

row, $\quad \mathrm{R}=\mathrm{r}_{1}+\mathrm{r}_{2} \quad$ and, column, $\mathrm{C}=\mathrm{c}_{1}+\mathrm{c}_{2}-1$ 
Therefore, $\quad r_{1} c_{1}+r_{2} c_{2}=\left(r_{1}+r_{2}\right)\left(c_{1}+c_{2}-1\right)------------------->(i)$

When, $\quad r_{1}+r_{2}>n$

then, row, $\mathrm{R}=\mathrm{r}_{1}+\mathrm{r}_{2}-\mathrm{n}$ and, column, $\mathrm{C}=\mathrm{c}_{1}+\mathrm{c}_{2}$

therefore, $\quad r_{1} c_{1}+r_{2} c_{2}=\left(r_{1}+r_{2}-n\right)\left(c_{1}+c_{2}\right)$

(ii). For addition of ' $\mathrm{p}$ ' numbers $\mathrm{N}_{1}, \mathrm{~N}_{2}, \mathrm{~N}_{3}, \ldots \ldots . . \mathrm{N}_{\mathrm{p}}$ taken from the same $\mathrm{CP}$ whose respective position in the

$\mathrm{CP}$ having ' $\mathrm{n}$ ' fixed rows be $\mathrm{r}_{1} \mathrm{c}_{1}, \mathrm{r}_{2} \mathrm{c}_{2}, \mathrm{r}_{3} \mathrm{c}_{3}, \ldots \ldots \ldots \mathrm{r}_{\mathrm{p}} \mathrm{c}_{\mathrm{p}}$. Let the outcome be $\mathrm{N}$ whose position is 'rc'. Then if,

$\mathrm{r}_{1}+\mathrm{r}_{2}+\mathrm{r}_{3}+\ldots \ldots \ldots+\mathrm{r}_{\mathrm{p}} \leq \mathrm{n}$

$\quad r=r_{1}+r_{2}+r_{3}+\ldots \ldots \ldots .+r_{p}$

and, column $\quad \mathrm{c}=\mathrm{c}_{1}+\mathrm{c}_{2}+\mathrm{c}_{3}+\ldots \ldots . .+\mathrm{c}_{\mathrm{p}}-(\mathrm{p}-1)$

If, $\quad \mathrm{n}<\mathrm{r}_{1}+\mathrm{r}_{2}+\mathrm{r}_{3}+\ldots \ldots \ldots . .+\mathrm{r}_{\mathrm{p}} \leq 2 \mathrm{n}$

then, row $r=r_{1}+r_{2}+r_{3}+\ldots \ldots \ldots . .+r_{p}-n$

and, column $\mathrm{c}=\mathrm{c}_{1}+\mathrm{c}_{2}+\mathrm{c}_{3}+\ldots \ldots . .+\mathrm{c}_{\mathrm{p}}-(\mathrm{p}-2)$

Therefore if, $\quad(\mathrm{a}-1) n<r_{1}+r_{2}+r_{3}+\ldots \ldots \ldots . .+r_{p} \leq$ an

where, $\quad a \in N$, and $a \leq p$

$r=r_{1}+r_{2}+r_{3}+\ldots \ldots \ldots .+r_{p}-(a-1) n-1 . \ldots+-$
$c=c_{1}+c_{2}+c_{3}+\ldots \ldots . .+c_{p}-(p-a)$

\subsection{Subtraction of numbers in $\mathbf{C P}$}

Let $\mathrm{N}_{1}$ and $\mathrm{N}_{2}$ be two numbers whose position in a CP having ' $\mathrm{n}$ ' fixed rows be denoted by $r_{1} c_{2}$ and $r_{2} c_{2}$ respectively. Then their difference $\mathrm{N}_{2}-\mathrm{N}_{1}$ is defined when,

(i) $\mathrm{c}_{2}>\mathrm{c}_{1}$, or (ii) $\mathrm{c}_{2}=\mathrm{c}_{1}, \mathrm{r}_{2}>\mathrm{r}_{1}$

Let the row-column of $\mathrm{N}=\mathrm{N}_{2}-\mathrm{N}_{1}$, be 'rc'.

Then, when $\quad r_{2}>r_{1}$

$\mathrm{rc}=\mathrm{r}_{2} \mathrm{c}_{2}-\mathrm{r}_{1} \mathrm{c}_{1}=\left(\mathrm{r}_{2}-\mathrm{r}_{1}\right)\left(\mathrm{c}_{2}-\mathrm{c}_{1}+1\right)$

when, $r_{2} \leq r_{1}$

then, $\quad r c=r_{2} c_{2}-r_{1} c_{1}=\left(r_{2}+n-r_{1}\right)\left(c_{2}-c_{1}\right)$

\subsection{Multiplication of numbers in $\mathbf{C P}$}

(i). Let two numbers $\mathrm{N}_{1}$ and $\mathrm{N}_{2}$ having row-column position $\mathrm{r}_{1} \mathrm{c}_{1}$ and $\mathrm{r}_{2} \mathrm{c}_{2}$ be taken from a fixed CP having ' $\mathrm{n}$ ' number of total rows. Let ' $d$ ' be the common difference between any two successive elements. When $N_{1}$ is multiplied with $\mathrm{N}_{2}$, let the product be $\mathrm{N}$ having row-column position as ' $\mathrm{rc}$ '. When,

$\mathrm{r}_{1} \times \mathrm{r}_{2} \times \mathrm{d} \leq \mathrm{n}$

row, $r=r_{1} \times r_{2} \times d$

when, $\quad n<r_{1} \times r_{2} \times d \leq 2 n$,

$$
\mathrm{r}=\mathrm{r}_{1} \times \mathrm{r}_{2} \times \mathrm{d}-\mathrm{n}
$$

when, $\quad 2 \mathrm{n}<\mathrm{r}_{1} \times \mathrm{r}_{2} \times \mathrm{d} \leq 3 \mathrm{n}$

$\mathrm{r}=\mathrm{r}_{1} \times \mathrm{r}_{2} \times \mathrm{d}-2 \mathrm{n}$

$(\mathrm{a}-1) \mathrm{n}<\mathrm{r}_{1} \times \mathrm{r}_{2} \times \mathrm{d} \leq$ an

$\mathrm{r}=\mathrm{r}_{1} \times \mathrm{r}_{2} \times \mathrm{d}-(\mathrm{a}-1) \mathrm{n}$,

[where, ' $a$ ' is an integer]

In other words, we can determine the value of ' $r$ ' if the following in-equation is satisfied,

$0<r_{1} \times r_{2} \times d-a r \leq n \quad($ where, $a=n)$,

that implies $\quad r=r_{1} \times r_{2} \times d-r_{0} n$,

where $r_{0}$ is the greatest integer which satisfies the in-equation, $r_{0} n<r_{1} \times r_{2} \times d$.

The column, $\mathrm{c}=\left\lfloor\left\{\mathrm{n}\left(\mathrm{c}_{1}-1\right)+\mathrm{r}_{1}\right\}\left\{\mathrm{n}\left(\mathrm{c}_{2}-1\right)+\mathrm{r}_{2}\right\} \mathrm{d} / \mathrm{n}\right\rfloor$ [smallest integer function]

i.e. when a remainder is left, the quotient is promoted to the next higher integer, which gives the column.

(ii). Let us consider numbers, $\mathrm{N}_{1}, \mathrm{~N}_{2}, \mathrm{~N}_{3}, \ldots \ldots \ldots \ldots \mathrm{N}_{\mathrm{P}}$ taken from $\mathrm{CP}$ having ' $\mathrm{n}$ ' fixed rows and common difference ' $d$ '. Let their row-column position be $r_{1} c_{1}, r_{2} c_{2}, r_{3} c_{3} \ldots \ldots \ldots . r_{p} c_{p}$, respectively.

For product, $\quad \mathrm{N}_{1} \times \mathrm{N}_{2} \times \mathrm{N}_{3} \times \ldots \ldots \ldots . \mathrm{N}_{\mathrm{p}}$

(a) when, $\quad d^{(p-1)} r_{1} r_{2} r_{3} \ldots \ldots \ldots . . . . . r_{p} \leq n d$

row, $\quad r=d^{(p-1)} r_{1} r_{2} r_{3} \ldots \ldots \ldots . . . . r_{p}, \quad$ and column, $c=1$

(b)when, $\quad \mathrm{d}^{(\mathrm{p}-1)} \mathrm{r}_{1} \mathrm{r}_{2} \mathrm{r}_{3} \ldots \ldots \ldots \ldots . . . \mathrm{r}_{\mathrm{p}}>$ nd

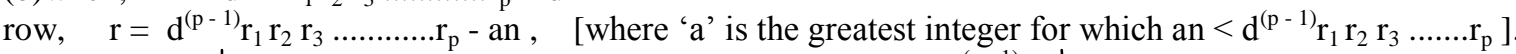
column, $\quad c=\left\{\left[n\left(c_{1}-1\right)+r_{1}\right\}\left\{n\left(c_{2}-1\right)+r_{2}\right\} \ldots \ldots \ldots\left\{n\left(c_{p}-1\right)+r_{p}\right\} d^{(p-1)} / n,\right]$ [smallest integer function mode]. If remainder is left while determining column, the quotient is increased to the next higher integer which determines the column. 
Note $\rightarrow$ In any $\mathrm{CP}$, if in the product of various numbers, if there is at least one element from the last row, then the product element will necessarily lie in the last row.

\subsection{Division of numbers in $\mathrm{CP}$}

In a column progression, division between two numbers may or may not be defined. Let ' $n$ ' be the total number of fixed rows of a $\mathrm{CP}$, and $\mathrm{N}_{1}, \mathrm{~N}_{2}$, be two numbers taken from it having row-column position $\mathrm{r}_{1} \mathrm{c}_{1}, \mathrm{r}_{2} \mathrm{c}_{2}$ respectively. Then their ratio is,

$$
\mathrm{N}_{1} / \mathrm{N}_{2}=\left\{\mathrm{n}\left(\mathrm{c}_{1}-1\right)+\mathrm{r}_{1}\right\} /\left\{\mathrm{n}\left(\mathrm{c}_{2}-1\right)+\mathrm{r}_{2}\right\}
$$

The result may or may not exist in the CP. The ratio is independent of choice of common difference ' $d$ '.

\subsection{Sum of all the numbers in a given column}

In any column progression (CP) having ' $n$ ' number of rows and ' $d$ ' being the common difference between any two successive elements, let ' $c$ ' be the column whose all elements sum is to be determined. Then, sum of all elements in the column is,

$\mathrm{S}_{\mathrm{c}}=\mathrm{nd}\{\mathrm{nc}+(1-\mathrm{n}) / 2\}$

\subsection{Sum of sum of columns}

(i). Supposing in a fixed ' $n$ ' row column progression having common difference ' $d$ ' between two successive elements, let $\mathrm{S}_{\mathrm{c} 1}, \mathrm{~S}_{\mathrm{c} 2}, \mathrm{~S}_{\mathrm{c} 3} \ldots \ldots . . . \mathrm{S}_{\mathrm{cp}}$ be the sum of columns $\mathrm{c}_{1}, \mathrm{c}_{2}, \mathrm{c}_{3}, \ldots \ldots \ldots . . . \mathrm{c}_{\mathrm{p}}$, respectively, whose further sum is to be determined. Then, sum of sum of the columns is,

$$
\begin{aligned}
& \mathrm{S}_{\mathrm{c}}=\mathrm{S}_{\mathrm{c} 1}+\mathrm{S}_{\mathrm{c} 2}+\mathrm{S}_{\mathrm{c} 3}+\ldots \ldots \ldots \ldots \ldots \ldots+\mathrm{S}_{\mathrm{cp}} \\
& \quad=\text { nd }\left\{\mathrm{nc}_{1}+(1-\mathrm{n}) / 2\right\}+\mathrm{nd}\left\{\mathrm{nc}_{2}+(1-\mathrm{n}) / 2\right\}+\ldots \ldots \ldots \ldots \ldots+\mathrm{nd}\left\{\mathrm{nc}_{\mathrm{p}}+(1-\mathrm{n}) / 2\right\}
\end{aligned}
$$

Therefore, $\mathrm{S}_{\mathrm{c}}=\mathrm{nd}\left\{\mathrm{n}\left(\mathrm{c}_{1}+\mathrm{c}_{2}+\mathrm{c}_{3}+\ldots \ldots \ldots+\mathrm{c}_{\mathrm{p}}\right)+\mathrm{p}(1-\mathrm{n}) / 2\right\}$

(ii). Let us suppose various CPs with, total fixed rows $n_{1}, n_{2}, n_{3}, \ldots \ldots . n_{r}$ each having common difference $d_{1}, d_{2}$, $\mathrm{d}_{3}, \ldots \ldots \ldots \mathrm{d}_{\mathrm{r}}$.

We know that sum of all the numbers in a given column is given by,

$\mathrm{S}_{\mathrm{c}}=\mathrm{nd}\{\mathrm{nc}+(1-\mathrm{n}) / 2\}$

Supposing from each of the CP members of one column or more is to be summed, such as from,

$$
\begin{aligned}
& \mathrm{n}_{1} ; \mathrm{c}_{11}, \mathrm{c}_{12}, \mathrm{c}_{13}, \ldots \ldots \ldots, \mathrm{c}_{1 \mathrm{p} 1} \\
& \mathrm{n}_{2} ; \mathrm{c}_{21}, \mathrm{c}_{22}, \mathrm{c}_{23}, \ldots \ldots \ldots \ldots . . . ., \mathrm{c}_{2 \mathrm{p} 2} \\
& \mathrm{n}_{3} ; \mathrm{c}_{31}, \mathrm{c}_{32}, \mathrm{c}_{33}, \ldots \ldots \ldots \ldots \ldots . ., \mathrm{c}_{3 \mathrm{p} 3} \\
& \mathrm{n}_{\mathrm{r}} ; \mathrm{c}_{\mathrm{r} 1}, \mathrm{c}_{\mathrm{r} 2}, \mathrm{c}_{\mathrm{r} 3}, \ldots \ldots \ldots \ldots \ldots \ldots, \mathrm{c}_{\mathrm{rpr}}
\end{aligned}
$$

Then their sum is, $\mathrm{S}=\mathrm{S}_{\mathrm{c} 1}+\mathrm{S}_{\mathrm{c} 2}+\mathrm{S}_{\mathrm{c} 3}+\ldots \ldots \ldots . . .+\mathrm{S}_{\mathrm{cr}}$

Therefore $\mathrm{S}=\mathrm{n}_{1} \mathrm{~d}_{1}\left\{\mathrm{n}_{1}\left(\mathrm{c}_{11}+\mathrm{c}_{12}+\mathrm{c}_{13}+\ldots \ldots \ldots . .+\mathrm{c}_{1 \mathrm{p} 1}\right)+\mathrm{p}_{1}\left(1-\mathrm{n}_{1}\right) / 2\right\}+\mathrm{n}_{2} \mathrm{~d}_{2}\left\{\mathrm{n}_{2}\left(\mathrm{c}_{21}+\mathrm{c}_{22}+\mathrm{c}_{23}+\ldots \ldots \ldots .\right.\right.$. $\left.\left.+\mathrm{c}_{2 \mathrm{p} 2}\right)+\mathrm{p}_{2}\left(1-\mathrm{n}_{2}\right) / 2\right\}+\ldots \ldots \ldots \ldots \ldots \ldots+\mathrm{n}_{\mathrm{r}} \mathrm{d}_{\mathrm{r}}\left\{\mathrm{n}_{\mathrm{r}}\left(\mathrm{c}_{\mathrm{r} 1}+\mathrm{c}_{\mathrm{r} 2}+\mathrm{c}_{\mathrm{r} 3}+\ldots \ldots \ldots \ldots \ldots \ldots+\mathrm{c}_{\mathrm{rpr}}\right)+\mathrm{p}_{\mathrm{r}}\left(1-\mathrm{n}_{\mathrm{r}}\right) / 2\right\}$

(iii). Determination of row-column of sum of different columns for a given CP.

Let ' $n$ ' be the total number of fixed rows. Let $c_{1}, c_{2}, c_{3}, \ldots \ldots \ldots ., c_{p}$ be the columns whose sum be $c_{s}$.

That is, $\mathrm{c}_{\mathrm{s}}=\mathrm{c}_{1}+\mathrm{c}_{2}+\mathrm{c}_{3}+\ldots \ldots \ldots+\mathrm{c}_{\mathrm{p}}$.

For determining row-column position of sum of all elements of $c_{1}, c_{2}, c_{3}, \ldots \ldots \ldots c_{p}$, two cases arise.

Case I: (a). When ' $n$ ' is even and ' $p$ ' is odd.

row, $r=n / 2$ and column, $c=\mathrm{nc}_{\mathrm{s}}-(\mathrm{np}-\mathrm{p}-1) / 2 \quad$ [where, $\mathrm{n}, \mathrm{c}, \mathrm{p} \in \mathrm{I}$ ]

' $p$ ' denotes the number of columns participating in the summing procedure.

(b). when ' $n$ ' is even and ' $p$ ' is even

row, $\mathrm{r}=\mathrm{n}$ and column, $\mathrm{c}=\mathrm{nc}_{\mathrm{s}}-\mathrm{p}(\mathrm{n}-1) / 2$

Case II: when ' $n$ ' is odd and ' $p$ ' is odd or even

row, $\mathrm{r}=\mathrm{n}$ and column, $\mathrm{c}=\mathrm{nc}_{\mathrm{s}}-\mathrm{p}(\mathrm{n}-1) / 2$

Note $\rightarrow$ In all cases as discussed relating to sum of elements in a given column; the sum of elements for any given column exceeds that of the preceding column by $\mathrm{n}^{2} \mathrm{~d}$. In other words, the sum of elements of $1 \mathrm{st}$ column, 2nd column, 3rd column,......... p th column, becomes a sort of arithmetic progression in which the first element is the sum of elements of 1 st column and common difference is $n^{2} d$. That is, first element, $\quad a=n(n+1) d / 2$ and c.d. $=\mathrm{n}^{2} \mathrm{~d}$

\subsection{Subtraction between sum of numbers in columns}

Let there be a fixed ' $n$ ' row CP having common difference ' $d$ ' between any two successive elements. Let there be two columns $c_{x}$ and $c_{y}$ chosen from the given CP such that $c_{x}>c_{y}$.

$\mathrm{Sc}_{\mathrm{x}}\left(\right.$ sum of elements of column $\left.\mathrm{c}_{\mathrm{x}}\right)=\mathrm{nd}\left\{\mathrm{nc}_{\mathrm{x}}-(\mathrm{n}-1) / 2\right\}$

$\mathrm{Sc}_{\mathrm{y}}$ (sum of elements of column $\mathrm{c}_{\mathrm{y}}$ ) $=\mathrm{nd}\left\{\mathrm{nc}_{\mathrm{y}^{-}}(\mathrm{n}-1) / 2\right\}$ 
$\mathrm{S}=\mathrm{Sc}_{\mathrm{x}}-\mathrm{Sc}_{\mathrm{y}}=\operatorname{nd}\left\{\mathrm{n}\left(\mathrm{c}_{\mathrm{x}}-\mathrm{c}_{\mathrm{y}}\right)\right\}=\mathrm{n}^{2} \mathrm{~d}\left(\mathrm{c}_{\mathrm{x}}-\mathrm{c}_{\mathrm{y}}\right)$

For determining row-column of $\mathrm{S}$,

row, $\mathrm{r}=\mathrm{n}$ and column, $\mathrm{c}=\mathrm{n}\left(\mathrm{c}_{\mathrm{x}}-\mathrm{c}_{\mathrm{y}}\right)$

2.10. Let us suppose two fixed-row column progression having total number of fixed rows ' $n_{1}$ ' and ' $n_{2}$ ' and let the common difference between two successive elements in them be ' $\mathrm{d}_{1}$ ' and ' $\mathrm{d}_{2}$ ' respectively. If sum of numbers in column $c_{y}$ is to be subtracted from sum of numbers in column $c_{x}$; where ' $c_{x}$ ' is from CP having total fixed rows ' $\mathrm{n}_{1}$ ' and $\mathrm{c}_{\mathrm{y}}$ from $\mathrm{CP}$ having total fixed rows' $\mathrm{n}_{2}$ ', then, $\mathrm{Sc}_{\mathrm{x}}=\mathrm{n}_{1} \mathrm{~d}_{1}\left\{\mathrm{n}_{1} \mathrm{c}_{\mathrm{x}}-\left(\mathrm{n}_{1}-1\right) / 2\right\} \quad$ and $\quad \mathrm{Sc}_{\mathrm{y}}=\mathrm{n}_{2} \mathrm{~d}_{2}\left\{\mathrm{n}_{2} \mathrm{c}_{\mathrm{y}}-\left(\mathrm{n}_{2}-1\right) / 2\right\}$

$\mathrm{S}=\mathrm{Sc}_{\mathrm{x}}-\mathrm{Sc}_{\mathrm{y}}=\mathrm{n}_{1} \mathrm{~d}_{1}\left\{\mathrm{n}_{1} \mathrm{c}_{\mathrm{x}}-\left(\mathrm{n}_{1}-1\right) / 2\right\}-\mathrm{n}_{2} \mathrm{~d}_{2}\left\{\mathrm{n}_{2} \mathrm{c}_{\mathrm{y}}-\left(\mathrm{n}_{2}-1\right) / 2\right\}$

\section{Row Progression (RP)}

Consider an array as such:

rows

\begin{tabular}{|c|c|c|c|c|c|c|c|c|c|}
\hline & $\mathrm{c}_{1}$ & $\mathrm{c}_{2}$ & $c_{3}$ & $\mathrm{c}_{4}$ & $\mathrm{c}_{5}$ & $\mathrm{c}_{6}$ & $\mathrm{c}_{7}$ & $\mathrm{c}_{8}$ & $\mathrm{c}_{9}$ \\
\hline $\mathrm{r}_{1}$ & 1 & 2 & 3 & 4 & 5 & 6 & 7 & 8 & 9 \\
\hline$r_{2}$ & 10 & 11 & 12 & 13 & 14 & 15 & 16 & 17 & 18 \\
\hline$r_{3}$ & 19 & 20 & 21 & 22 & 23 & 24 & 25 & 26 & 27 \\
\hline $\mathrm{r}_{4}$ & 28 & 29 & 30 & 31 & 32 & 33 & 34 & 35 & 36 \\
\hline $\mathrm{r}_{5}$ & 37 & 38 & 39 & 40 & 41 & 42 & 43 & 44 & 45 \\
\hline$r_{6}$ & 46 & 47 & 48 & 49 & 50 & 51 & 52 & 53 & 54 \\
\hline$r_{7}$ & 55 & 56 & 57 & 58 & 59 & 60 & 61 & 62 & 63 \\
\hline$r_{8}$ & 64 & 65 & 66 & 67 & 68 & 69 & 70 & 71 & 72 \\
\hline \multirow[t]{3}{*}{$\mathrm{r}_{9}$} & 73 & 74 & 75 & 76 & 77 & 78 & 79 & 80 & 81 \\
\hline & : & : & : & : & : & : & : & : & : \\
\hline & : & : & : & 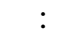 & : & : & & . & \\
\hline
\end{tabular}

The number of columns increases progressively horizontally to a fixed maximum value of 9 . The number of rows increases vertically downwards and there is no upper limit. This sort of progression is called 'Fixed-Column Row Progression' or simply 'Row Progression (RP) '. In this section we shall consider an array where the column-row progression is arithmetic and whose common difference between any two successive elements is the first element of the column-row progression.

\subsection{To find a number with a given row and column in RP}

Let the total number of columns be ' $\mathrm{m}$ ' for any fixed-column row progression (RP) having a common difference ' $d$ ' between two successive elements. To determine the number $\mathrm{N}$ in ' $\mathrm{c}$ 'th column and ' $\mathrm{r}$ 'th row, we use the formula,

$$
\mathrm{N}=\mathrm{m}(\mathrm{r}-1) \mathrm{d}+\mathrm{cd}
$$

\subsection{To find the column-row of a given number in RP}

For a given fixed-column row progression; if a number, $\mathrm{N}$, is given and we have to find its row and column, then we use,

(a). row, $\quad \mathrm{r}=\left\lfloor\frac{N}{m d}\right\rfloor, \quad$ such that $[\mathrm{N} \leq \mathrm{mrd}<\mathrm{N}+\mathrm{md}, \mathrm{r} \in \mathrm{I}]$

(i.e. ' $r$ ' is the smallest integer for which, $m r d \geq N$ )

(b). column, $c=N / d-m(r-1) \quad$ [where ' $r$ ' is the row obtained earlier]

\subsection{Addition of numbers in RP}

(i). Let there be two numbers $\mathrm{N}_{1}$ and $\mathrm{N}_{2}$, taken from a row progression (RP) having ' $\mathrm{m}$ ' fixed-columns. Supposing $\mathrm{N}_{1}$ to be in the $\mathrm{c}_{1}$ th column and $\mathrm{r}_{1}$ th row and $\mathrm{N}_{2}$ to be in $\mathrm{c}_{2}$ th column and $\mathrm{r}_{2}$ th row, then, in their addition, the row and column of their sum can be determined as:

when, $\quad c_{1}+c_{2} \leq m$ then, column, $\quad c=c_{1}+c_{2} \quad$ and row, $\quad r=r_{1}+r_{2}-1$

Therefore, $\quad c_{1} r_{1}+c_{2} r_{2}=\left(c_{1}+c_{2}\right)_{c}\left(r_{1}+r_{2}-1\right)_{r}$

when, $c_{1}+c_{2}>m$ then, column, $c=c_{1}+c_{2}-m$ and row, $r=r_{1}+r_{2}$

Therefore, $\quad c_{1} r_{1}+c_{2} r_{2}=\left(c_{1}+c_{2}-m\right)_{c}\left(r_{1}+r_{2}\right)_{r}$

(ii). For addition of numbers, $\mathrm{N}=\mathrm{N}_{1}+\mathrm{N}_{2}+\mathrm{N}_{3}+\ldots \ldots \ldots \ldots \ldots . . . . . . . \mathrm{N}_{\mathrm{P}}$, whose respective position in the RP of ' $\mathrm{m}$ '

fixed columns be as, $\quad c_{1} r_{1}, c_{2} r_{2}, c_{3} r_{3}, \ldots \ldots \ldots \ldots c_{p} r_{p}$. Let the column-row of $\mathrm{N}$ be 'cr'.

when, $\quad \mathrm{c}_{1}+\mathrm{c}_{2}+\mathrm{c}_{3}+\ldots \ldots \ldots \ldots \ldots+\mathrm{c}_{\mathrm{p}} \leq \mathrm{m}$,

then, column, $\mathrm{c}=\mathrm{c}_{1}+\mathrm{c}_{2}+\mathrm{c}_{3}+\ldots \ldots \ldots \ldots \ldots+\mathrm{c}_{\mathrm{p}}$ and

row, $\quad \begin{aligned} \mathrm{r}= & \mathrm{r}_{1}+\mathrm{r}_{2}+\mathrm{r}_{3}+\ldots \ldots \ldots \ldots \ldots+\mathrm{r}_{\mathrm{p}}-(\mathrm{p}-1) \\ \text { when, } & \mathrm{m}<\mathrm{c}_{1}+\mathrm{c}_{2}+\mathrm{c}_{3}+\ldots \ldots \ldots \ldots \ldots \ldots+\mathrm{c}_{\mathrm{p}} \leq 2 \mathrm{~m},\end{aligned}$

then, column, $\quad \mathrm{c}=\mathrm{c}_{1}+\mathrm{c}_{2}+\mathrm{c}_{3}+\ldots \ldots \ldots \ldots \ldots+\mathrm{c}_{\mathrm{p}}-\mathrm{m}$, and 
row,

$$
\mathrm{r}=\mathrm{r}_{1}+\mathrm{r}_{2}+\mathrm{r}_{3}+\ldots \ldots \ldots \ldots \ldots+\mathrm{r}_{\mathrm{p}}-(\mathrm{p}-2)
$$

when,

$(\mathrm{a}-1) \mathrm{m}<\mathrm{c}_{1}+\mathrm{c}_{2}+\mathrm{c}_{3}+\ldots \ldots \ldots \ldots \ldots+\mathrm{c}_{\mathrm{p}} \leq \mathrm{am}$

then, column, $\quad c=c_{1}+c_{2}+c_{3}+\ldots \ldots \ldots \ldots \ldots+c_{p}-(a-1) m$

and row, $\quad \mathrm{r}=\mathrm{r}_{1}+\mathrm{r}_{2}+\mathrm{r}_{3}+\ldots \ldots \ldots \ldots \ldots+\mathrm{r}_{\mathrm{p}}-(\mathrm{p}-\mathrm{a})$

$[a \in I]$

\subsection{Subtraction of numbers in RP}

Let ' $\mathrm{m}$ ' be the total number of fixed columns and, $\mathrm{N}_{1}$ and $\mathrm{N}_{2}$ be two numbers in a RP denoted by column-row position, $\mathrm{c}_{1} \mathrm{r}_{1}$ and $\mathrm{c}_{2} \mathrm{r}_{2}$, respectively, such that $\mathrm{N}_{1}>\mathrm{N}_{2}$.

Then, (i). $\quad \mathrm{N}_{1}-\mathrm{N}_{2}=\mathrm{c}_{1} \mathrm{r}_{1}-\mathrm{c}_{2} \mathrm{r}_{2}=\left(\mathrm{c}_{1}-\mathrm{c}_{2}\right)_{\mathrm{c}}\left(\mathrm{r}_{1}-\mathrm{r}_{2}+1\right)_{\mathrm{r}}$, for $\mathrm{c}_{1}>\mathrm{c}_{2}$

(ii). $\mathrm{N}_{1}-\mathrm{N}_{2}=\mathrm{c}_{1} \mathrm{r}_{1}-\mathrm{c}_{2} \mathrm{r}_{2}=\left(\mathrm{c}_{1}+\mathrm{m}-\mathrm{c}_{2}\right)_{\mathrm{c}}\left(\mathrm{r}_{1}-\mathrm{r}_{2}\right)_{\mathrm{r}}$, for $\mathrm{c}_{1} \leq \mathrm{c}_{2}$

The operation is defined only when $r_{1}>r_{2}$, or when $r_{1}=r_{2}$, then $c_{1}>c_{2}$.

\subsection{Multiplication of numbers in RP}

(i). Let ' $\mathrm{m}$ ' be the total number of fixed columns and, $\mathrm{N}_{1}$ and $\mathrm{N}_{2}$ be two numbers in a RP denoted by columnrow position, $c_{1} r_{1}$ and $c_{2} r_{2}$, respectively, that are to be multiplied. Let ' $d$ ' be the common difference between two successive elements.
When,
$\mathrm{c}_{1} \mathrm{c}_{2} \mathrm{~d} \leq \mathrm{m}$,
when,
$\mathrm{m}<\mathrm{c}_{1} \mathrm{c}_{2} \mathrm{~d} \leq 2 \mathrm{~m}$,
then, column, $\mathrm{c}=\mathrm{c}_{1} \mathrm{c}_{2} \mathrm{~d}$
when,
$2 \mathrm{~m}<\mathrm{c}_{1} \mathrm{c}_{2} \mathrm{~d} \leq 3 \mathrm{~m}$,
then, column, $\quad c=c_{1} c_{2} d-m$,
then, column, $c=c_{1} c_{2} d-2 m$,

when, $\quad(\mathrm{a}-1) \mathrm{m}<\mathrm{c}_{1} \mathrm{c}_{2} \mathrm{~d} \leq \mathrm{am}, \quad$ then, column, $\quad \mathrm{c}=\mathrm{c}_{1} \mathrm{c}_{2} \mathrm{~d}-(\mathrm{a}-1) \mathrm{m}$,

we get the value of ' $c$ ' for which the following in-equation is satisfied;

$0<\mathrm{c}_{1} \mathrm{c}_{2} \mathrm{~d}-\mathrm{cm} \leq \mathrm{m}, \quad \mathrm{c}=\mathrm{c}_{1} \mathrm{c}_{2} \mathrm{~d}-\mathrm{c}_{0} \mathrm{~m}$, [where $\mathrm{c}_{0}$ is the greatest integer for which $\mathrm{c}_{0} \mathrm{~m}<\mathrm{c}_{1} \mathrm{c}_{2} \mathrm{~d}$ ]

For determining the row, $\quad \mathrm{r}=\left\lfloor\left\{\mathrm{m}\left(\mathrm{r}_{1}-1\right)+\mathrm{c}_{1}\right\} \quad\left\{\mathrm{m}\left(\mathrm{r}_{2}-1\right)+\mathrm{c}_{2}\right\} \mathrm{d} / \mathrm{m}\right\rfloor$, [smallest integer function] In case the numerator is not completely divisible the quotient is rounded off to the next higher integer.

(ii). Let us consider numbers, $\mathrm{N}_{1}, \mathrm{~N}_{2}, \mathrm{~N}_{3} \ldots \ldots \ldots \ldots . \mathrm{N}_{\mathrm{P}}$ taken from a fixed- 'm'-column row progression having common difference ' $d$ ' between two successive elements. Let their respective column-row position be, $c_{1} r_{1}$, $\mathrm{c}_{2} \mathrm{r}_{2}, \mathrm{c}_{3} \mathrm{r}_{3}, \ldots \ldots \ldots \ldots \ldots . . . \mathrm{c}_{\mathrm{p}} \mathrm{r}_{\mathrm{p}}$, respectively.

For, $\quad \mathrm{N}_{1} \times \mathrm{N}_{2} \times \mathrm{N}_{3} \times \ldots \ldots \ldots \ldots . . . . . \mathrm{N}_{\mathrm{P}}$

when, $\quad \mathrm{d}^{(\mathrm{p}-1)} \mathrm{c}_{1} \mathrm{c}_{2} \mathrm{c}_{3} \ldots \ldots . . \mathrm{c}_{\mathrm{p}} \leq \mathrm{md}, \quad$ column, $\mathrm{c}=\mathrm{d}^{(\mathrm{p}-1)} \mathrm{c}_{1} \mathrm{c}_{2} \mathrm{c}_{3} \ldots \ldots . \mathrm{c}_{\mathrm{p}} \quad$ and, row, $\mathrm{r}=1$

when, $\quad \mathrm{d}^{(\mathrm{p}-1)} \mathrm{c}_{1} \mathrm{c}_{2} \mathrm{c}_{3} \ldots \ldots . . . \mathrm{c}_{\mathrm{p}}>\mathrm{md}$, then the column ' $\mathrm{c}$ ' is a natural number such that,

$\mathrm{c}=\mathrm{d}^{(\mathrm{p}-1)} \mathrm{c}_{1} \mathrm{c}_{2} \mathrm{c}_{3} \ldots \ldots \ldots \mathrm{c}_{\mathrm{p}}-\mathrm{mc}_{0}$ [where $\mathrm{c}_{0}$ is the greatest integer for which, $\mathrm{mc}_{0}<\mathrm{d}^{(\mathrm{p}-1)} \mathrm{c}_{1} \mathrm{c}_{2} \mathrm{c}_{3} \ldots . . \mathrm{c}_{\mathrm{p}}$ ]

For determining the row, $\quad r=\left\lfloor\left\{m\left(r_{1}-1\right)+c_{1}\right\}\left\{m\left(r_{2}-1\right)+c_{2}\right\} \ldots \ldots \ldots\left\{m\left(r_{p}-1\right)+c_{p}\right\} d^{(p-1)} / m\right\rfloor$, where ' $r$ ' is an integer (following smallest integer function mode). If after division in the right hand side of the equation, remainder is left then the quotient is increased to the next higher integer which determines the row.

\subsection{Division of numbers in RP}

Let ' $\mathrm{m}$ ' be the total number of fixed columns and, $\mathrm{N}_{1}$ and $\mathrm{N}_{2}$ be two numbers in a RP denoted by column-row position, $\mathrm{c}_{1} \mathrm{r}_{1}$ and $\mathrm{c}_{2} \mathrm{r}_{2}$, respectively. Then, $\mathrm{N}=\mathrm{N}_{1} / \mathrm{N}_{2}=\left[\mathrm{m}\left(\mathrm{r}_{1}-1\right)+\mathrm{c}_{1}\right] /\left[\mathrm{m}\left(\mathrm{r}_{2}-1\right)+\mathrm{c}_{2}\right]$. The result may or may not exist in the RP.

Determination of column-row position.

Row position of $\mathrm{N}, \mathrm{r}=\left\lfloor\frac{\mathrm{r} 1}{\mathrm{~m}(\mathrm{r} 2-1) \mathrm{d}+\mathrm{c} 2 \mathrm{~d}}\right\rfloor, \quad[\mathrm{r} \in \mathrm{I}$, following the smallest integer function mode $]$

Column position of $\mathrm{N}, \mathrm{c}=\left[\left\{\mathrm{m}\left(\mathrm{r}_{1}-1\right)+\mathrm{c}_{1}\right\}\right] /\left[\mathrm{d}\left\{\mathrm{m}\left(\mathrm{r}_{2}-1\right)+\mathrm{c}_{2}\right\}\right] \leq \mathrm{m}$

when, $\mathrm{m}<\left[\left\{\mathrm{m}\left(\mathrm{r}_{1}-1\right)+\mathrm{c}_{1}\right\}\right] /\left[\mathrm{d}\left\{\mathrm{m}\left(\mathrm{r}_{2}-1\right)+\mathrm{c}_{2}\right\}\right] \leq 2 \mathrm{~m}$, then column, $\mathrm{c}=\left[\left\{\mathrm{m}\left(\mathrm{r}_{1}-1\right)+\mathrm{c}_{1}\right\}\right] /\left[\mathrm{d}\left\{\mathrm{m}\left(\mathrm{r}_{2}-1\right)+\mathrm{c}_{2}\right\}\right]-\mathrm{m}$

when, $(\mathrm{p}-1) \mathrm{m}<\left[\left\{\mathrm{m}\left(\mathrm{r}_{1}-1\right)+\mathrm{c}_{1}\right\}\right] /\left[\mathrm{d}\left\{\mathrm{m}\left(\mathrm{r}_{2}-1\right)+\mathrm{c}_{2}\right\}\right] \leq \mathrm{pm}$,

then column, $c=\left[\left\{\mathrm{m}\left(\mathrm{r}_{1}-1\right)+\mathrm{c}_{1}\right\}\right] /\left[\mathrm{d}\left\{\mathrm{m}\left(\mathrm{r}_{2}-1\right)+\mathrm{c}_{2}\right\}\right]-(\mathrm{p}-1) \mathrm{m}, \quad[\mathrm{p} \in \mathrm{I}]$

In case 'c' comes out to be a fraction the column is taken as the integer that is nearest to the quotient.

\subsection{Sum of all the numbers in a given row in $\mathbf{R P}$}

$\mathrm{S}_{\mathrm{r}}=\mathrm{md}\{(\mathrm{m}+1) / 2+\mathrm{m}(\mathrm{r}-1)\}$

where ' $\mathrm{m}$ ' is the total number of fixed columns, ' $\mathrm{r}$ ' is the given row and ' $\mathrm{d}$ ' is the common difference between any two successive elements.

Therefore, $\mathrm{S}_{\mathrm{r}}=\mathrm{md}\{\mathrm{mr}-(\mathrm{m}-1) / 2\}$

3.8.Sum of sum of elements of various rows in $\mathbf{R P}$

Let, $\mathrm{Sr}_{1}, \mathrm{Sr}_{2}, \mathrm{Sr}_{3}, \ldots \ldots \ldots \ldots \ldots . . \mathrm{Sr}_{\mathrm{p}}$ be the sum of rows $\mathrm{r}_{1}, \mathrm{r}_{2}, \mathrm{r}_{3}, \ldots \ldots \ldots \ldots \mathrm{r}_{\mathrm{p}}$, respectively.

Then, $\quad \mathrm{S}=\mathrm{Sr}_{1}+\mathrm{Sr}_{2}+\mathrm{Sr}_{3}+\ldots \ldots \ldots \ldots \ldots+\mathrm{Sr}_{\mathrm{p}}$ 
$\mathrm{S}=\mathrm{md}\left\{\mathrm{mr}_{1}+(1-\mathrm{m}) / 2\right\}+\mathrm{md}\left\{\mathrm{mr}_{2}+(1-\mathrm{m}) / 2\right\}+$. $+\mathrm{md}\left\{\mathrm{mr}_{\mathrm{p}}+(1-\mathrm{m}) / 2\right\}$

Therefore $\mathrm{S}=\mathrm{md}\left\{\mathrm{m}\left(\mathrm{r}_{1}+\mathrm{r}_{2}+\mathrm{r}_{3}+\ldots\right.\right.$ $\left.\left.+r_{p}\right)-p(m-1) / 2\right\}$

\subsection{Determination of column-row of sum of numbers of given rows in a $R \mathbf{P}$}

Let $r_{\mathrm{s}}$ (sum of elements up to given row $)=r_{1}+r_{2}+r_{3}+\ldots \ldots \ldots \ldots \ldots \ldots+r_{p}$.

Case I. (a). When ' $m$ ' is even and ' $p$ ' is even

column, $\mathrm{c}=\mathrm{m}, \quad$ and row, $\mathrm{r}=\mathrm{mr}_{\mathrm{s}}-\mathrm{p}(\mathrm{m}-1) / 2$

(b). When ' $m$ ' is even and ' $p$ ' is odd

column, $\quad c=m / 2$ and row, $r=m_{s}-(m p-p-1) / 2$

Case II. When ' $m$ ' is odd and ' $p$ ' is even or odd.

column, $\mathrm{c}=\mathrm{m} \quad$ and row, $\mathrm{r}=\mathrm{mr}_{\mathrm{s}}-(\mathrm{m}-1) \mathrm{p} / 2$

3.10. Now let us suppose RPs with total fixed columns; $m_{1}, m_{2}, m_{3}, \ldots \ldots \ldots . . . m_{p}$ each having common difference between its successive elements, $d_{1}, d_{2}, d_{3}, \ldots \ldots \ldots . . . d_{p}$ respectively. Sum of numbers in a given row,

$\mathrm{S}_{\mathrm{r}}=\mathrm{md}\{\mathrm{mr}+(1-\mathrm{m}) / 2\}$.

Supposing from each RP one or more row is to be summed, such as from

$\mathrm{m}_{1} ; \mathrm{r}_{11}, \mathrm{r}_{12}, \mathrm{r}_{13}, \ldots \ldots \ldots \ldots \ldots . . . \mathrm{r}_{1 \mathrm{p} 1}$

$\mathrm{m}_{2} ; \mathrm{r}_{21}, \mathrm{r}_{22}, \mathrm{r}_{23}, \ldots \ldots \ldots \ldots \ldots . . . \mathrm{r}_{2 \mathrm{p} 2}$

$\mathrm{m}_{3} ; \mathrm{r}_{31}, \mathrm{r}_{32}, \mathrm{r}_{33}, \ldots \ldots \ldots \ldots \ldots . . . \mathrm{r}_{3 \mathrm{p} 3}$

$\mathrm{m}_{\mathrm{p}} ; \mathrm{r}_{\mathrm{p} 1}, \mathrm{r}_{\mathrm{p} 2}, \mathrm{r}_{\mathrm{p} 3}, \ldots \ldots \ldots \ldots \ldots . . . . \mathrm{r}_{\mathrm{ppp}}$

Then, $\quad \mathrm{Sr}_{1}=\mathrm{m}_{1} \mathrm{~d}_{1}\left\{\mathrm{~m}_{1}\left(\mathrm{r}_{11}+\mathrm{r}_{12}+\mathrm{r}_{13}+\ldots \ldots \ldots \ldots \ldots . .+\mathrm{r}_{1 \mathrm{p} 1}\right)-\mathrm{p}_{1}\left(\mathrm{~m}_{1}-1\right) / 2\right\}$

$\mathrm{Sr}_{2}=\mathrm{m}_{2} \mathrm{~d}_{2}\left\{\mathrm{~m}_{2}\left(\mathrm{r}_{21}+\mathrm{r}_{22}+\mathrm{r}_{23}+\ldots \ldots \ldots \ldots+\mathrm{r}_{2 \mathrm{p} 2}\right)-\mathrm{p}_{2}\left(\mathrm{~m}_{2}-1\right) / 2\right\}$

And so on up to the ' $p$ ' th term.

Therefore, sum of all the sums, $\mathrm{S}=\mathrm{Sr}_{1}+\mathrm{Sr}_{2}+\mathrm{Sr}_{3}+\ldots \ldots \ldots \ldots+\mathrm{Sr}_{\mathrm{p}}$

$\mathrm{S}=\left[\mathrm{m}_{1} \mathrm{~d}_{1}\left\{\mathrm{~m}_{1}\left(\mathrm{r}_{11}+\mathrm{r}_{12}+\mathrm{r}_{13}+\ldots \ldots+\mathrm{r}_{1 \mathrm{p} 1}\right)-\mathrm{p}_{1}\left(\mathrm{~m}_{1}-1\right) / 2\right\}+\mathrm{m}_{2} \mathrm{~d}_{2}\left\{\mathrm{~m}_{2}\left(\mathrm{r}_{21}+\mathrm{r}_{22}+\mathrm{r}_{23}+\ldots \ldots+\mathrm{r}_{2 \mathrm{p} 2}\right)-\mathrm{p}_{2}\left(\mathrm{~m}_{2}-1\right) / 2\right\}\right.$

$\left.+\ldots \ldots \ldots \ldots \ldots \ldots . . .+m_{p} d_{p}\left\{m_{p}\left(r_{p 1}+r_{p 2}+r_{p 3}+\ldots \ldots \ldots+r_{p p p}\right)-p_{p}\left(m_{p}-1\right) / 2\right\}\right]$

\subsection{Subtraction between sum of numbers in rows in $\mathbf{R P}$}

(i).Let there be a fixed-' $m$ '-column row progression (RP), with common difference ' $d$ '. Let the sum of numbers of row ' $r_{x}$ ' be subtracted from sum of numbers of row $r_{y}$.

Therefore, $\quad \mathrm{Sr}_{\mathrm{x}}=\mathrm{md}\left\{\mathrm{mr}_{\mathrm{x}}-(\mathrm{m}-1) / 2\right\} \quad$ and $\quad \mathrm{Sr}_{\mathrm{y}}=\mathrm{md}\left\{\mathrm{mr}_{\mathrm{y}^{-}}(\mathrm{m}-1) / 2\right\}$

The difference $\mathrm{S}=\mathrm{Sr}_{\mathrm{x}}-\mathrm{Sr}_{\mathrm{y}}=\mathrm{md}\left\{\mathrm{m}\left(\mathrm{r}_{\mathrm{x}}-\mathrm{r}_{\mathrm{y}}\right)\right\}=\mathrm{m}^{2} \mathrm{~d}\left\{\mathrm{r}_{\mathrm{x}}-\mathrm{r}_{\mathrm{y}}\right\}, \quad\left[\mathrm{r}_{\mathrm{x}}>\mathrm{r}_{\mathrm{y}}\right]$

Row of $S, r=m\left(r_{x}-r_{y}\right)$ and column, $c=m$

(ii).Now, let us assume two fixed-column row progression (RP) having total number of fixed columns ' $\mathrm{m}_{1}$ ' and ' $\mathrm{m}_{2}$ ' and let the common difference in them be ' $\mathrm{d}_{1}$ ' and ' $\mathrm{d}_{2}$ ', respectively. If sum of numbers in row ' $\mathrm{r}_{\mathrm{x}}$ ', where $r_{x}$ is from RP having total fixed columns ' $m_{1}$ ' and ' $r_{y}$ ' from RP having total fixed columns ' $\mathrm{m}_{2}$ '. Then,

$\mathrm{Sr}_{\mathrm{x}}=\mathrm{m}_{1} \mathrm{~d}_{1}\left\{\mathrm{~m}_{1} \mathrm{r}_{\mathrm{x}}-\left(\mathrm{m}_{1}-1\right) / 2\right\} \quad$ and $\quad \mathrm{Sr}_{\mathrm{y}}=\mathrm{m}_{2} \mathrm{~d}_{2}\left\{\mathrm{~m}_{2} \mathrm{r}_{\mathrm{y}}-\left(\mathrm{m}_{2}-1\right) / 2\right\}$

$\mathrm{S}=\mathrm{Sr}_{\mathrm{x}}-\mathrm{Sr}_{\mathrm{y}}=\mathrm{m}_{1} \mathrm{~d}_{1}\left\{\mathrm{~m}_{1} \mathrm{r}_{\mathrm{x}}-\left(\mathrm{m}_{1}-1\right) / 2\right\}-\mathrm{m}_{2} \mathrm{~d}_{2}\left\{\mathrm{~m}_{2} \mathrm{r}_{\mathrm{y}}-\left(\mathrm{m}_{2}-1\right) / 2\right\}$

\subsection{Determination of column-row of sum of elements for a given column and up to a given row}

Let ' $m$ ' be the total number of fixed columns of a given column row progression. Let $c_{1}$ be the column and $r_{1}$ be the row up to which column-row position of sum of elements is to be determined. Then for determining column of the sum of elements,

$\mathrm{c}=\mathrm{r}_{1} \mathrm{c}_{1}-\mathrm{c}_{0} \mathrm{~m}$, [where $\mathrm{c}_{0}$ is the greatest integer for which $\mathrm{c}_{0} \mathrm{~m}<\mathrm{r}_{1} \mathrm{c}_{1}$ ]

row, $r=r_{1}\left(r_{1}-1\right) / 2+\left\lfloor\frac{c 1 r 1}{m}\right\rfloor \quad$ [smallest integer function mode]. [If ' $c_{1} r_{1} / m$ ' comes out in fraction the quotient is promoted to the next higher integer].

3.13. For determining column-row of sum of elements of two or more columns up to any row, first individual column-row positions of the sum of elements of a given column is determined and then further determination of column-row takes place by addition rule. Let $\mathrm{c}_{1}, \mathrm{c}_{2}, \mathrm{c}_{3}, \ldots \ldots \ldots . ., \mathrm{c}_{\mathrm{p}}$ be the columns and $\mathrm{r}_{1}, \mathrm{r}_{2}, \mathrm{r}_{3}, \ldots \ldots \ldots \ldots . . . \mathrm{r}_{\mathrm{p}}$ be the respective rows up to which sum of columns is to be determined. If $S_{1}, S_{2}, S_{3}, \ldots \ldots \ldots . . ., S_{p}$ be the sum of respective column and up to respective row, then column-row of $S=S_{1}+S_{2}+S_{3}+\ldots \ldots \ldots . .+S_{p}$ is determined as

column, $\quad \mathrm{c}=\left[\left\{\mathrm{c}_{1} \mathrm{r}_{1}-\mathrm{c}_{01} \mathrm{~m}\right\}+\left\{\mathrm{c}_{2} \mathrm{r}_{2}-\mathrm{c}_{02} \mathrm{~m}\right\}+\ldots \ldots \ldots .+\left\{\mathrm{c}_{\mathrm{p}} \mathrm{r}_{\mathrm{p}}-\mathrm{c}_{0 \mathrm{p}} \mathrm{m}\right\}\right]-\mathrm{c}_{0} \mathrm{~m}, \quad\left[\right.$ where $\mathrm{c}_{01}, \mathrm{c}_{02}, \mathrm{c}_{03}, \ldots \ldots, \mathrm{c}_{0 \mathrm{p}}, \mathrm{c}_{0} \in \mathrm{I}$, and each of them are the greatest integer for which the corresponding difference is a positive number].

Row, $\left.\mathrm{r}=\left[\left\{\mathrm{r}_{1}\left(\mathrm{r}_{1}-1\right) / 2+\left|\mathrm{c}_{1} \mathrm{r}_{1} / \mathrm{m}\right|\right\}+\left\{\mathrm{r}_{2}\left(\mathrm{r}_{2}-1\right) / 2+\mathrm{k}_{2} \mathrm{r}_{2} / \mathrm{m}\right\}+\ldots \ldots \ldots \ldots+\left\{\mathrm{r}_{\mathrm{p}}\left(\mathrm{r}_{\mathrm{p}}-1\right) / 2+\mathrm{k}_{\mathrm{p}} \mathrm{r}_{\mathrm{p}} / \mathrm{m}\right\rfloor\right\}-\left(\mathrm{p}-\mathrm{c}_{0}-1\right)\right],[$ where, $\mathrm{c}_{\mathrm{p}} \mathrm{r}_{\mathrm{p}} / \mathrm{m}$, follows smallest integer function mode]

Note $\rightarrow$ Some new points have been added in this CR progression which were not discussed under RC progression. But it matters not, for $\mathrm{CR}$ and $\mathrm{RC}$ progression are basically similar and anything in general can be applied to either of them. 
IV. General Form of Row \& Column Progression

(whose first member may not be equal to the common difference) Consider the following arrays:

\begin{tabular}{ccccccccccccc} 
& \multicolumn{10}{c}{ Array I } \\
& $\mathrm{c}_{1}$ & $\mathrm{c}_{2}$ & $\mathrm{c}_{3}$ & $\mathrm{c}_{4}$ & $\mathrm{c}_{5}$ & $\mathrm{c}_{6}$ & $\mathrm{c}_{7}$ & $\mathrm{c}_{8}$ & $\mathrm{c}_{9}$ & $\mathrm{c}_{10}$ & $\mathrm{c}_{11}$ \\
$\mathrm{r}_{1}$ & 5 & 29 & 53 & 77 & 101 & 125 & 149 & 173 & 197 & 221 & $:::$ \\
$\mathrm{r}_{2}$ & 8 & 32 & 56 & 80 & 104 & 128 & 152 & 176 & 200 & 224 & $::::$ \\
$\mathrm{r}_{3}$ & 11 & 35 & 54 & 83 & 107 & 131 & 155 & 179 & 203 & 227 & $::::$ \\
$\mathrm{r}_{4}$ & 14 & 38 & 62 & 86 & 110 & 134 & 158 & 182 & 206 & 230 & $::::$ \\
$\mathrm{r}_{5}$ & 17 & 41 & 65 & 89 & 113 & 137 & 161 & 185 & 209 & 233 & $:::$ \\
$\mathrm{r}_{6}$ & 20 & 44 & 68 & 92 & 116 & 140 & 164 & 188 & 212 & 236 & $:::$ \\
$\mathrm{r}_{7}$ & 23 & 47 & 71 & 95 & 119 & 143 & 167 & 191 & 215 & 239 & $:::$ \\
$\mathrm{r}_{8}$ & 26 & 50 & 74 & 98 & 122 & 146 & 170 & 194 & 218 & 242 & $:::$
\end{tabular}

\section{Array II}

$\begin{array}{cccccccccc} & \mathrm{c}_{1} & \mathrm{c}_{2} & \mathrm{c}_{3} & \mathrm{c}_{4} & \mathrm{c}_{5} & \mathrm{c}_{6} & \mathrm{c}_{7} & \mathrm{c}_{8} & \mathrm{c}_{9} \\ \mathrm{r}_{1} & 1 & 29 & 106 & 232 & 407 & 631 & 904 & 1226 & :::: \\ \mathrm{r}_{2} & 2 & 37 & 121 & 254 & 436 & 667 & 947 & 1276 & :::: \\ \mathrm{r}_{3} & 4 & 46 & 137 & 277 & 466 & 704 & 991 & 1327 & :::: \\ \mathrm{r}_{4} & 7 & 56 & 154 & 301 & 497 & 742 & 1036 & 1379 & ::: \\ \mathrm{r}_{5} & 11 & 67 & 172 & 326 & 529 & 781 & 1082 & 1432 & :::: \\ \mathrm{r}_{6} & 16 & 79 & 191 & 352 & 562 & 821 & 1129 & 1486 & ::: \\ \mathrm{r}_{7} & 22 & 92 & 211 & 379 & 596 & 862 & 1177 & 1541 & :::\end{array}$

4.1. Let ' $\mathrm{n}$ ' be the number of rows which are fixed in row-column progression (RCP), having common difference ' $d$ ' between any two successive elements (as in the above array I). Let ' $a$ ' be the first element of $\mathrm{RCP}$. For determination of a number, $\mathrm{N}$ whose row -column position is ' $\mathrm{rc}$ ',

$$
\mathrm{N}=\mathrm{n}(\mathrm{c}-1) \mathrm{d}+\mathrm{rd}+\mathrm{a}-\mathrm{d}=\mathrm{nd}(\mathrm{c}-1)+\mathrm{d}(\mathrm{r}-1)+\mathrm{a}
$$

4.2. If a number, $\mathrm{N}$ is given then for determining its row-column position, column, $\quad \mathrm{c}=[(\mathrm{N}-\mathrm{a}+\mathrm{d}) / \mathrm{nd}], \quad$ [smallest integer function] row, $\quad \mathrm{r}=(\mathrm{N}-\mathrm{a}+\mathrm{d}) / \mathrm{d}-\mathrm{n}(\mathrm{c}-1)$, [where ' $\mathrm{c}$ ' is the column as determined above.]

4.3. Consider a situation as shown in array II. Here the common difference, ' $d$ ' is not fixed but varies with increasing position. But the variation of ' $\mathrm{d}$ ' is fixed, that is, common difference between any two successive ' $\mathrm{d}$ ' is constant. To determine a number, $\mathrm{N}$, whose row-column position is ' $r c$ ' in a fixed-' $n$ '-row $\mathrm{CP}$ with ' $\mathrm{d}_{1}$ ' being the common difference (between 2 nd and 1st element) and ' $a$ ' being the first element.

$\mathrm{N}=\left\{\mathrm{nd}_{1}(\mathrm{c}-1)+\mathrm{rd}_{1}\right\}\left\{\mathrm{nd}_{1}(\mathrm{c}-1)+\mathrm{rd}_{1}-1\right\} / 2+\mathrm{a}$

4.4. For determination of row-column position of a number, $\mathrm{N}$ as discussed earlier in situation as shown in array II, first we have to determine the position 'p' of the number in the CP. If 'a' be the first element , then

$$
\mathrm{a}+\mathrm{p}(\mathrm{p}-1) / 2=\mathrm{N}
$$

column, $\quad c=\left|p / \mathrm{nd}_{1}\right|$, [smallest integer function]

For determining the row; the numerator in the mixed fraction having denominator ' $\mathrm{n}$ ' is the row.

$\mathrm{c}=\left\lfloor\frac{1}{n}\right\rfloor$, [where ' $\mathrm{r}$ ' gives the row, and $\ln +\mathrm{r}=\mathrm{p}$ ]

and, row, $r=p / d_{1}-n(c-1)$

\subsection{Multiplication of numbers in RCP}

When the first element in any RCP is 1 , then whatever be the value of common difference ' $\mathrm{d}$ ', the product of any elements necessarily lies in the RCP table. If the c.d. 'd' between any two successive elements is 1, then for whatever value of ' $a$ ' (first element) the product will necessarily lie in the RCP table. For other cases (except when ' $a$ ' and ' $d$ ' are equal) the product element between any two numbers in RCP table does not (in most cases) lie in the RCP table. But then we have to consider an external number not present in the RCP.

The best way for determining if the product of any number in a given RCP will lie in the RCP table is, d $\leq$ a ......(i). (necessary but in-sufficient condition).

This is true for any RCP which satisfies the above in-equation. In other words, if common difference is equal or less than the first element of the RCP then the product of numbers in the given RCP will lie in the RCP table. If $\mathrm{d}>\mathrm{a}$, the product will not lie in the RCP table.

The other condition is that, if ' $a$ ' is even, ' $d$ ' should be odd and if ' $d$ ' is even ' $a$ ' should be odd....(ii) But this condition can be relaxed if ' $d$ ' is a factor of ' $a$ ', for all $d \leq a$.

Let us consider a set of numbers $\mathrm{N}_{1}, \mathrm{~N}_{2}, \mathrm{~N}_{3}, \ldots \ldots \ldots . . . \mathrm{N}_{\mathrm{p}}$ taken from fixed-' $\mathrm{n}$ '-row $\mathrm{CP}$ having common difference ' $d$ ' between any two elements. Let row-column positions of these numbers be $r_{1} c_{1}, r_{2} c_{2}, r_{3} c_{3}, \ldots \ldots \ldots ., r_{p} c_{p}$ respectively. 
For $\mathrm{N}=\mathrm{N}_{1} \times \mathrm{N}_{2} \times \mathrm{N}_{3} \times \ldots \ldots \ldots \mathrm{N}_{\mathrm{p}}$

$$
\left.\mathrm{N}=\left[\left\{\text { nd }\left(\mathrm{c}_{1}-1\right)+\mathrm{d}\left(\mathrm{r}_{1}-1\right)+\mathrm{a}\right\}\left\{\text { nd }\left(\mathrm{c}_{2}-1\right)+\mathrm{d}\left(\mathrm{r}_{2}-1\right)+\mathrm{a}\right\} \ldots \ldots \ldots \ldots . . \ldots \mathrm{nd}\left(\mathrm{c}_{\mathrm{p}}-1\right)+\mathrm{d}\left(\mathrm{r}_{\mathrm{p}}-1\right)+\mathrm{a}\right\}\right]
$$

4.6. Determination of row-column position of product of two numbers, $\mathrm{N}_{1}$ and $\mathrm{N}_{2}$, whose row-column position are $r_{1} c_{1}$ and $r_{2} c_{2}$ respectively. Let the RCP having ' $n$ ' fixed rows with common difference ' $d$ ' between any two successive elements satisfy the criteria for the product of numbers to be in the RCP table. Let 'a' be the first element. Then $\mathrm{N}=\mathrm{N}_{1} \times \mathrm{N}_{2}$. Let row-column of $\mathrm{N}$ be ' $\mathrm{rc}$ '.

Row, $\quad r=\left[\left\{\left(r_{1}-1\right) d+a\right\}\left(r_{2}-1\right)+r_{1}-r_{0} n\right], \quad$ [where $r_{0}$ is the greatest integer for which ' $r$ ' has a positive value] Column, $\quad \mathrm{c}=\left\lfloor\left[\mathrm{d}-\mathrm{a}+\left\{\mathrm{nd}\left(\mathrm{c}_{1}-1\right)+\mathrm{d}\left(\mathrm{r}_{1}-1\right)+\mathrm{a}\right\}\left\{\mathrm{nd}\left(\mathrm{c}_{2}-1\right)+\mathrm{d}\left(\mathrm{r}_{2}-1\right)+\mathrm{a}\right\}\right] / \mathrm{nd}\right\rfloor$, [smallest integer function]

4.7.Sum of elements of a given column

Let ' $n$ ' be the total number of fixed rows and ' $d$ ' be the common difference between any two consecutive elements. Let ' $a$ ' be the first element. For sum of all elements of the c'th column,

$\mathrm{S}_{\mathrm{c}}=[\mathrm{nd}\{\mathrm{nc}-(\mathrm{n}-1) / 2\}+\mathrm{n}(\mathrm{a}-\mathrm{d})]$

\subsection{Sum of sum of the columns}

Let $\mathrm{Sc}_{1}, \mathrm{Sc}_{2}, \mathrm{Sc}_{3}, \ldots \ldots, \mathrm{Sc}_{\mathrm{p}}$, be the sum of all elements of columns $\mathrm{c}_{1}, \mathrm{c}_{2}, \mathrm{c}_{3}, \ldots \ldots \ldots, \mathrm{c}_{\mathrm{p}}$ respectively. $\mathrm{Sc}=\mathrm{Sc}_{1}+\mathrm{Sc}_{2}+\mathrm{Sc}_{3}+\ldots \ldots \ldots \ldots+\mathrm{Sc}_{\mathrm{p}}$

$\mathrm{Sc}=\left[\mathrm{nd}\left\{\mathrm{n}\left(\mathrm{c}_{1}+\mathrm{c}_{2}+\mathrm{c}_{3}+\ldots \ldots \ldots \ldots+\mathrm{c}_{\mathrm{p}}\right)+\mathrm{p}(1-\mathrm{n}) / 2\right\}+\mathrm{pn}(\mathrm{a}-\mathrm{d})\right]$

\subsection{Sum of elements for a given row up to a given column}

Let ' $n$ ' be the total number of fixed rows of a given RCP whose first element is ' $a$ ', having a constant common difference ' $d$ '. Then for determining sum of elements of ' $r$ 'th' row up to the ' $c$ 'th' column,

$\mathrm{S}_{1 \rightarrow \mathrm{c}}=[\{(\mathrm{r}-1) \mathrm{d}+\mathrm{a}\} \mathrm{c}+\mathrm{ncd}(\mathrm{c}-1) / 2]$

4.10.If sum of numbers for a given row ' $r$ ' is to be determined from column ' $c_{1}$ ' to ' $c_{2}$ ', then, first ' $a$ ' is determined.

$\mathrm{a}^{\prime}=\mathrm{nd}\left(\mathrm{c}_{1}-1\right)+\mathrm{d}(\mathrm{r}-1)+\mathrm{a}$

$$
\mathrm{S}_{\mathrm{c} 1 \rightarrow \mathrm{c} 2}=\mathrm{a}^{\prime}\left(\mathrm{c}_{2}-\mathrm{c}_{1}+1\right)+\left[\mathrm{nd}\left(\mathrm{c}_{2}-\mathrm{c}_{1}\right)\left(\mathrm{c}_{2}-\mathrm{c}_{1}+1\right) / 2\right]
$$

\subsection{Subtraction of sum of numbers in column}

Let $\mathrm{Sc}_{\mathrm{y}}$ be subtracted from $S c_{\mathrm{x}}$ from a given RCP. Then, $\mathrm{S}=\mathrm{Sc}_{\mathrm{x}}-\mathrm{Sc}_{\mathrm{y}}=\mathrm{n}^{2} \mathrm{~d}\left(\mathrm{c}_{\mathrm{x}}-\mathrm{c}_{\mathrm{y}}\right)$

If the RCP are different and $\mathrm{n}_{1}, \mathrm{n}_{2} ; \mathrm{a}_{1}, \mathrm{a}_{2} ; \mathrm{d}_{1}, \mathrm{~d}_{2} ; \mathrm{c}_{\mathrm{x}}, \mathrm{c}_{\mathrm{y}}$ be their respective - total number of fixed rows, first element, common difference between two consecutive numbers, and the given column, respectively, then

$$
\mathrm{S}=\mathrm{Sc}_{\mathrm{x}}-\mathrm{Sc}_{\mathrm{y}}=\mathrm{n}_{1}\left[\mathrm{~d}_{1}\left\{\mathrm{n}_{1} \mathrm{c}_{\mathrm{x}}-\left(\mathrm{n}_{1}-1\right) / 2\right\}+\left(\mathrm{a}_{1}-\mathrm{d}_{1}\right)\right]-\mathrm{n}_{2}\left[\mathrm{~d}_{2}\left\{\mathrm{n}_{2} \mathrm{c}_{\mathrm{y}}-\left(\mathrm{n}_{2}-1\right) / 2\right\}+\left(\mathrm{a}_{2}-\mathrm{d}_{2}\right)\right]
$$

\section{Array III}

$\begin{array}{clcccccc} & \mathrm{c}_{1} & \mathrm{c}_{2} & \mathrm{c}_{3} & \mathrm{c}_{4} & \mathrm{c}_{5} & \mathrm{c}_{6} & \mathrm{c}_{7} \\ \mathrm{r}_{1} & 2 & 110 & 410 & 902 & 1586 & 2462 & :::: \\ \mathrm{r}_{2} & 5 & 137 & 461 & 977 & 1685 & 2582 & :::: \\ \mathrm{r}_{3} & 11 & 167 & 515 & 1055 & 1787 & 2711 & :::: \\ \mathrm{r}_{4} & 20 & 200 & 572 & 1136 & 1892 & 2840 & :::: \\ \mathrm{r}_{5} & 32 & 236 & 632 & 1220 & 2000 & 2972 & :::: \\ \mathrm{r}_{6} & 47 & 275 & 695 & 1307 & 2111 & 3107 & :::: \\ \mathrm{r}_{7} & 65 & 317 & 761 & 1397 & 2225 & 3245 & :::: \\ \mathrm{r}_{8} & 86 & 362 & 830 & 1490 & 2342 & 3386 & ::::\end{array}$

4.12.(i) This array is similar to array II. In such cases for determining the number in a given row or column we have to first find the position of the number and then determine its value. For a fixed-' $n$ '-row CP the number in the ' $r$ 'th' row and ' $c$ 'th' column is determined as ,

position, $\quad \mathrm{p}=\mathrm{n}(\mathrm{c}-1)+\mathrm{r}$

$\mathrm{N}=\mathrm{a}+\mathrm{p}(\mathrm{p}-1) \mathrm{d}_{1} / 2, \quad$ [where $\mathrm{d}_{1}$ is the difference between 2 nd element and 1 st element]

(ii) Determination of row-column position of a given number, $\mathrm{N}$, taken from $\mathrm{CP}$ as illustrated in array III.

Column, $\mathrm{c}=\lfloor\mathrm{p} / \mathrm{nd}\rfloor, \quad$ or $\mathrm{c}=\left\lfloor 1 \frac{r}{n}\right\rfloor, \quad$ [ where, $\mathrm{p}=\ln +\mathrm{r}$, and' $\mathrm{r}$ ' gives the row]

(iii). Sum of given column of elements

Let ' $n$ ' be the total number of fixed rows, ' $d$ ' be the first common difference and ' $a$ ' be the first element. Let ' $c$ ' be the column whose sum is to be determined.

Therefore, position, $\quad \mathrm{p}=\mathrm{n}(\mathrm{c}-1), \quad[$ ' $\mathrm{p}$ ' is the position of the number that is next to begin with summing] Sum of elements, $\mathrm{Sc}=\mathrm{na}+\mathrm{nd} \mathrm{p}(\mathrm{p}+1) / 2+\mathrm{nd}[\mathrm{p}(\mathrm{n}-1)-\mathrm{p}(\mathrm{n}-1) / 2+\mathrm{n}(\mathrm{n}-1) / 2-(\mathrm{n}-1)(2 \mathrm{n}-1) / 6]$

$\mathrm{Sc}=\mathrm{na}+\mathrm{nd}[\mathrm{p}(\mathrm{p}+1) / 2+\mathrm{p}(\mathrm{n}-1) / 2+\mathrm{n}(\mathrm{n}-1) / 2-(\mathrm{n}-1)(2 \mathrm{n}-1) / 6]$ 
(iv). For determining sum of numbers of a given row ' $r$ ' up to a given column ' $c$ ', with ' $a$ ' being the first element, ' $d$ ' the first common difference and ' $n$ ' the total number of fixed rows of the RCP;

$\mathrm{S}_{\rightarrow} \mathrm{c}=\mathrm{r}+(\mathrm{r}+\mathrm{n})+(\mathrm{r}+2 \mathrm{n})+(\mathrm{r}+3 \mathrm{n})+\ldots \ldots \ldots \ldots .+\{\mathrm{r}+(\mathrm{c}-1) \mathrm{n}\}$

$\mathrm{S}_{\rightarrow} \mathrm{c}=\mathrm{a}+\mathrm{r}(\mathrm{r}-1) \mathrm{d} / 2+\mathrm{a}+(\mathrm{n}+\mathrm{r})(\mathrm{n}+\mathrm{r}-1) \mathrm{d} / 2+\mathrm{a}+(\mathrm{r}+2 \mathrm{n})(\mathrm{r}+2 \mathrm{n}-1) \mathrm{d} / 2+\ldots \ldots \ldots+\mathrm{a}+\{\mathrm{r}+(\mathrm{c}-1) \mathrm{n}\}\{\mathrm{r}+(\mathrm{c}-1) \mathrm{n}-$

$1\} \mathrm{d} / 2$

$\mathrm{S}_{\rightarrow} \mathrm{c}=\mathrm{ac}+\mathrm{d} / 2 \sum_{c=1}^{c} \cdot\left[\mathrm{r}^{2}-\mathrm{r}+2 \mathrm{rn}(\mathrm{c}-1)+(\mathrm{c}-1)^{2} \mathrm{n}^{2}-\mathrm{n}(\mathrm{c}-1)\right]$

$\mathrm{S}_{\rightarrow} \mathrm{c}=\mathrm{ac}+\mathrm{d} / 2 \times\left[\mathrm{rc}(\mathrm{r}-1)+\mathrm{ncr}(\mathrm{c}-1)+\mathrm{n}^{2} \mathrm{c}(\mathrm{c}-1)(2 \mathrm{c}-1) / 6-\mathrm{nc}(\mathrm{c}-1) / 2\right]$

\section{Periodic Row Column Progression}

(I) Discontinuous Simple Harmonic Progression (dSHP)

Consider an array as such:

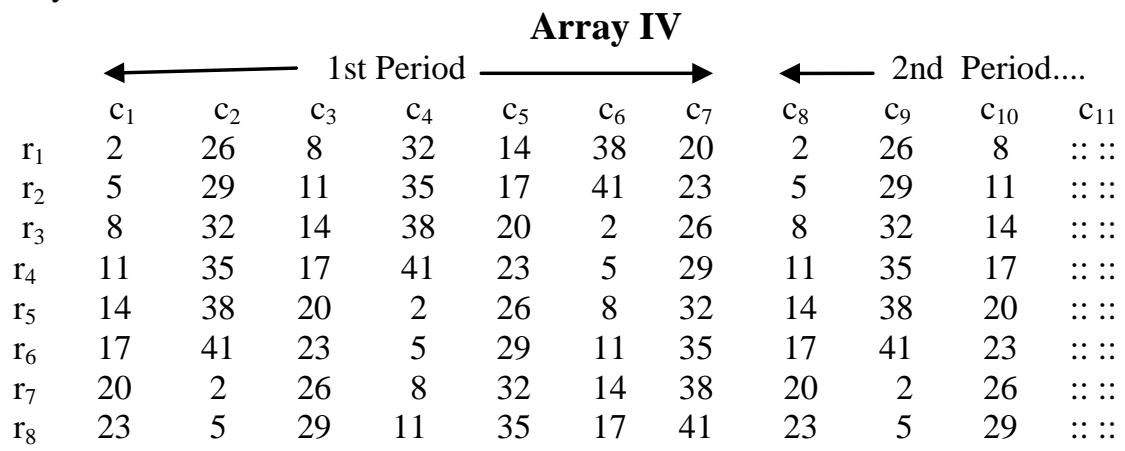

In such a system of progression we observe that exactly after the end of 7th column; the 8th column repeats the 1 st column, the 9 th column repeats the 2 nd column and so on and so forth. Therefore such sort of column which progresses to a maximum number ' $t$ ' and repeats all its elements once again is said to be periodic having a period equal to ' $\mathrm{T}$ '.

For any given row ' $r_{1}$ ' extending to a column ' $t$ ', the row contains all the elements of the period. We may further note that there is periodicity in every row-column progression. For example in array I, the last digit of 1st row varies as $5,9,3,7,1,5,9,3,7,1, \ldots \ldots .$. So it has a period of 5 . In array II, in any row, two odds and two evens alternate with each other. In array III, there are two numbers divisible by 10 after every $2,3,4, \ldots \ldots$ columns in the last row. This sort of column has increasing periodicity. But for distinguishing these periodic properties of RCP earlier discussed from that of array IV, let us call the progression as shown in array IV, as Simple Harmonic Progression (SHP). The others are periodic but not Harmonic Progression (HP).

5(I).1. To determine the position of given number in Simple Harmonic Progression (SHP)

Let there be a SHP with ' $a$ ' being the 1 st element, ' $d$ ' being the common difference between any two consecutive elements in first ' $k$ ' non-repeated elements and ' $n$ ' be the total number of rows of the RCP. Then for determining row-column of the number $\mathrm{N}_{\mathrm{x}}$ in the given RCP, first we determine its position. The subscript ' $\mathrm{x}$ ' is determining the number $\mathrm{N}$ repeated $(\mathrm{x}-1)$ times.

Therefore, position of $\mathrm{N}_{\mathrm{x}}, \quad \mathrm{p}=[(\mathrm{x}-1) \mathrm{k}+(\mathrm{N}-\mathrm{a}) / \mathrm{d}+1]$

\section{5(I).2. For determining the number for a given row-column position in SHP}

Let there be a SHP with ' $a$ ' being the 1st element, ' $d$ ' being the common difference between any two consecutive elements in first ' $k$ ' non-repeated elements and ' $n$ ' be the total number of rows of the RCP. If 'rc' be the row-column position of any number, $\mathrm{N}$, then for determining the number, the position is determined first. Position, $\quad \mathrm{p}=\mathrm{n}(\mathrm{c}-1)+\mathrm{r}$

As ' $\mathrm{k}$ ' is total number of first non-repeated elements, then

$$
\mathrm{t}_{1}=\mathrm{p}-\mathrm{t}_{0} \mathrm{k}, \quad \text { [where' } \mathrm{t}_{0} \text { ' is the greatest integer for which ' } \mathrm{t}_{1} \text { ' has a positive value] }
$$

Number, $\quad \mathrm{N}=\mathrm{a}+\left(\mathrm{t}_{1}-1\right) \mathrm{d}$

5(I).3.Frequency of elements in a given column

Frequency gives total number of occurrence of an element.

$\mathrm{f}_{\mathrm{c}}=($ Total number of rows in column $) /($ Total number of distinct elements $)=\mathrm{n} / \mathrm{k}$

5(I).4. Periodicity: For determining the number of columns in a period.

$\mathrm{T}($ period $)=($ Total number of distinct elements $) /($ H.C.F. of total no. of distinct elements \& fixed rows $)$

Therefore, $\mathrm{T}($ period $)=\mathrm{k} /$ H.C.F. of $(\mathrm{k} \& \mathrm{n}), \quad$ [H.C.F. is highest common factor]

5(I).5. Frequency of elements for a given period

$\mathrm{f}_{\mathrm{T}}=($ Total number of fixed rows $) /($ H.C.F. of total no. of distinct elements and fixed rows)

$\mathrm{f}_{\mathrm{T}}=\mathrm{n} /($ H.C.F. of $\mathrm{k} \& \mathrm{n})$ 
5(I).6. Yielding Position: It is the position in the SHP where the continuity of the progression breaks and numbers are repeated afresh. Yielding positions are $\mathrm{k}+1,2 \mathrm{k}+1,3 \mathrm{k}+1, \ldots \ldots \ldots, \mathrm{mk}+1$, [where $\mathrm{m} \in \mathrm{I}]$. Number of yielding positions per period is one less than frequency of any element per period. Therefore, $n(Y . P)=.f_{T}-1$ Determination of row-column position of yielding position gives Yielding Points.

Therefore, column, $\mathrm{c}=\lfloor\mathrm{p} / \mathrm{n}\rfloor$, and again, $\mathrm{c}=\left\lfloor\frac{1}{n}\right\rfloor$, [where, $\mathrm{p}=\ln +\mathrm{r}$, and ' $\mathrm{r}$ ' gives the row]

\section{5(I).7.Sum of elements of a given column}

(i). (a). When the column 'c' does not have yielding positions.

If ' $n$ ' be the total number of fixed rows, ' $d$ ' be the c.d., ' $k$ ' be the total number of distinct elements, ' $a$ ' be the first element, and ' $\mathrm{Sc}$ ' be the sum of elements of column ' $\mathrm{c}$ '. Then, first element of the column, $\mathrm{N}=\mathrm{a}+\left(\mathrm{t}_{1}-1\right) \mathrm{d}, \quad$ [as discussed earlier]

Therefore, $\quad \mathrm{Sc}=\mathrm{n}\{2 \mathrm{~N}+(\mathrm{n}-1) \mathrm{d}\} / 2$

(b). When column 'c' has one or more yielding positions

Let ' $r$ ' be the row in which yielding position is obtained, and let ' $t$ ' be the maximum number in the SHP. For one yielding position,

$\mathrm{Sc}=(\mathrm{n}-\mathrm{r}+1) / 2\{2 \mathrm{a}+(\mathrm{n}-\mathrm{r}) \mathrm{d}\}+(\mathrm{r}-1)\{2 \mathrm{t}-(\mathrm{r}-2) \mathrm{d}\} / 2$,

Sum for two or more yielding positions in a given column can be similarly solved.

(ii). As, all the columns get repeated after period ' $\mathrm{T}$ ', so

$\mathrm{Sc}_{\mathrm{i}}=\mathrm{S}\left(\mathrm{T}+\mathrm{c}_{\mathrm{i}}\right)=\mathrm{S}\left(2 \mathrm{~T}+\mathrm{c}_{\mathrm{i}}\right)=\mathrm{S}\left(3 \mathrm{~T}+\mathrm{c}_{\mathrm{i}}\right) \ldots \ldots \ldots \ldots$. [where, $\mathrm{Sc}_{\mathrm{i}}$ is sum of all elements of $\mathrm{c}_{\mathrm{i}}$ th column]

(iii). If period ' $\mathrm{T}$ ' is odd, then let $\mathrm{c}_{(\mathrm{x}+1) / 2}$ be the middle column in a period. Then $\mathrm{c}_{\mathrm{x}}$ will be the last column of the period. And,

$\mathrm{Sc}_{1}+\mathrm{Sc}_{\mathrm{x}}=\mathrm{Sc}_{2}+\mathrm{Sc}_{\mathrm{x}-1}=\mathrm{Sc}_{3}+\mathrm{Sc}_{\mathrm{x}-2}=$ $=2 \mathrm{Sc}_{(\mathrm{x}+1) / 2}$

If period ' $\mathrm{T}$ ' is even, let $\mathrm{c}_{\mathrm{x}}$ be the last column. Then the two middle columns are $\mathrm{c}_{\mathrm{x} / 2}$ and $\mathrm{c}_{(\mathrm{x}+2) / 2}$

It follows that sum of columns are as such:

$\mathrm{Sc}_{1}+\mathrm{Sc}_{\mathrm{x}}=\mathrm{Sc}_{2}+\mathrm{Sc}_{\mathrm{x}-1}=\mathrm{Sc}_{3}+\mathrm{Sc}_{\mathrm{x}-3}=$ $=\mathrm{Sc}_{\mathrm{x} / 2}+\mathrm{Sc}_{(\mathrm{x}+2) / 2}$ where $\mathrm{Sc}_{1}, \mathrm{Sc}_{2}, \mathrm{Sc}_{3}$

. $\mathrm{Sc}_{\mathrm{x}}$ are sum of elements of 1 st, 2 nd, $3 \mathrm{rd}$ last column respectively, of the period.

5(I).8.Sum of elements in a given row up to a given period.

Let there be a SHP with ' $a$ ' being the 1 st element, ' $d$ ' being the common difference between any two consecutive elements and ' $k$ ' be the total number of distinct elements and ' $n$ ' be the total number of rows of the RCP. Let ' $h$ ' be the highest common factor of ' $n$ ' and ' $k$ '.

Case I. When, $\mathrm{h}=1$

Then a complete period is obtained in the SHP. For any row, extending to the end of the period, has all the elements of the period. So sum of all the elements in any row extending to the end of the period is given by,

$\mathrm{S}=\mathrm{k}\{2 \mathrm{a}+(\mathrm{k}-1) \mathrm{d}\} / 2$

Case II. When, $\mathrm{h} \neq 1$

Then an incomplete period is obtained. Every row of the period becomes deficient of some elements. Period is given by, $\mathrm{T}=\mathrm{k} / \mathrm{h}$

Number of elements in any row extending to the end of period $=\mathrm{T}=\mathrm{k} / \mathrm{h}$,

So number of elements deficient $=\mathrm{k}-\mathrm{k} / \mathrm{h}$

Since the rows becomes deficient of some elements, it is not directly possible to determine the sum of all the elements of a given row up to end of the period. But if carefully studied, the sum of elements of row 1 up to the end of period $\left(\mathrm{S}_{1}\right)$; row $2,\left(\mathrm{~S}_{2}\right)$; row $3,\left(\mathrm{~S}_{3}\right), \ldots \ldots$. becomes periodic with a period equal to ' $\mathrm{h}$ '. Also there is a fixed common difference between any two sum of elements. The common difference between sum of elements is determined as,

Sum of elements c.d., $d_{\mathrm{s}}=\mathrm{d} \times \mathrm{k} / \mathrm{h}$

Sum of all the elements $=\mathrm{k}\{2 \mathrm{a}+(\mathrm{k}-1) \mathrm{d}\} / 2$

Let ' $\mathrm{S}_{1}$ ' be the sum of elements of 1 st row up to the end of the period. Then,

$\mathrm{S}_{1}+\left(\mathrm{S}_{1}+\mathrm{dk} / \mathrm{h}\right)+\left(\mathrm{S}_{1}+2 \mathrm{dk} / \mathrm{h}\right)+\left(\mathrm{S}_{1}+3 \mathrm{dk} / \mathrm{h}\right)+\ldots \ldots \ldots .+\left(\mathrm{S}_{1}+(\mathrm{h}-1) \mathrm{dk} / \mathrm{h}\right)=\mathrm{k}\{2 \mathrm{a}+(\mathrm{k}-1) \mathrm{d}\} / 2$

$\mathrm{hS}_{1}+\mathrm{dk}(\mathrm{h}-1) / 2=\mathrm{k}\{2 \mathrm{a}+(\mathrm{k}-1) \mathrm{d}\} / 2$

$\mathrm{S}_{1}=[\mathrm{k}\{2 \mathrm{a}+(\mathrm{k}-1) \mathrm{d}\} / 2-\mathrm{dk}(\mathrm{h}-1) / 2] / \mathrm{h}$

And subsequently sum of any row can be determined.

Now consider an array as such:

\section{(II) Discontinuous Complex Harmonic Progression (dCHP)}

\begin{tabular}{cccccccccccc} 
& \multicolumn{10}{c}{ Array V } \\
& $\mathrm{c}_{1}$ & $\mathrm{c}_{2}$ & $\mathrm{c}_{3}$ & $\mathrm{c}_{4}$ & $\mathrm{c}_{5}$ & $\mathrm{c}_{6}$ & $\mathrm{c}_{7}$ & $\mathrm{c}_{8}$ & $\mathrm{c}_{9}$ & $\mathrm{c}_{10}$ & $\mathrm{c}_{11}$ \\
$\mathrm{r}_{1}$ & 2 & 26 & 20 & 11 & 35 & 23 & 8 & 32 & 14 & 38 & $:::$ \\
$\mathrm{r}_{2}$ & 5 & 29 & 23 & 14 & 2 & 26 & 11 & 35 & 17 & 41 & $:::$ \\
$\mathrm{r}_{3}$ & 8 & 2 & 26 & 17 & 5 & 29 & 14 & 38 & 20 & 44 & $:::$ \\
$\mathrm{r}_{4}$ & 11 & 5 & 29 & 20 & 8 & 32 & 17 & 41 & 23 & 2 & $:::$
\end{tabular}




$\begin{array}{cccccccccccc}\mathrm{r}_{5} & 14 & 8 & 32 & 23 & 11 & 35 & 20 & 2 & 26 & 5 & ::: \\ \mathrm{r}_{6} & 17 & 11 & 2 & 26 & 14 & 38 & 23 & 5 & 29 & 8 & ::: \\ \mathrm{r}_{7} & 20 & 14 & 5 & 29 & 17 & 2 & 26 & 8 & 32 & 11 & ::: \\ \mathrm{r}_{8} & 23 & 17 & 8 & 32 & 20 & 5 & 29 & 11 & 35 & 14 & ::::\end{array}$

This sort of progression in which the total number of distinct elements is not bound but increases with each yielding position, is called Complex Harmonic Progression (CHP). It is the simplest of the complex harmonic progression as there are others whose variance also combines increasing common difference.

In such a situation, to find the number, $N$, in a given row-column 'rc', we first find the position, $\quad p=n$ ( $c$ 1) $+r$, [ where ' $n$ ' is the total number of rows]. Let ' $k$ ' be the total number of distinct elements up to the first yielding position. Then $\mathrm{N}_{0}$ be the position of first appearance of the element.

$\mathrm{N}_{0}=\mathrm{p}-\{\mathrm{k}+(\mathrm{k}+1)+(\mathrm{k}+2)+\ldots \ldots \ldots . .+(\mathrm{k}+\mathrm{x}-1)\}$

$\mathrm{N}_{0}=\mathrm{p}-\{\mathrm{kx}+\mathrm{x}(\mathrm{x}-1) / 2\}, \quad$ [where ' $\mathrm{x}$ ' is an integer for which $\mathrm{N}_{0}$ has the least positive value]

Then the number, $\mathrm{N}=\mathrm{a}+\left(\mathrm{N}_{0}-1\right) \mathrm{d}$, [where ' $\mathrm{a}$ ' is the first element and ' $d$ ' is the c.d.]

In such a system there is periodicity, but not precisely defined.

Up till here, most of the things have been discussed only under CP. However, everything is applicable to RP, and the reader should grasp the basic idea. So long only discontinuous Simple Harmonic Progression was discussed in this section. The progression would progress gradually, arrive to a maximum, end abruptly and start once again anew. In the next section we shall consider a progression which gradually increases and decreases.

Consider an array as such:

\section{(III) Continuous Simple Harmonic Progression (cSHP)}

\begin{tabular}{|c|c|c|c|c|c|c|c|c|c|c|c|}
\hline & \multicolumn{11}{|c|}{ Array VI } \\
\hline & & peric & & & 2nd & od & & $3 \mathrm{rd}$ & & & $\ldots .$. \\
\hline & $\mathrm{c}_{1}$ & $\mathrm{c}_{2}$ & $\overrightarrow{c_{3}}$ & $\mathrm{c}_{4}$ & $\mathrm{c}_{5}$ & $\overrightarrow{c_{6}}$ & $c_{7}$ & $\mathrm{c}_{8}$ & $\overrightarrow{c_{9}}$ & $\mathrm{c}_{10}$ & $\mathrm{c}_{11}$ \\
\hline $\mathrm{r}_{1}$ & 1 & 9 & 9 & 1 & 9 & 9 & 1 & 9 & 9 & 1 & $::::$ \\
\hline$r_{2}$ & 2 & 10 & 8 & 2 & 10 & 8 & 2 & 10 & 8 & 2 & $::::$ \\
\hline$r_{3}$ & 3 & 11 & 7 & 3 & 11 & 7 & 3 & 11 & 7 & 3 & $::::$ \\
\hline$r_{4}$ & 4 & 12 & 6 & 4 & 12 & 6 & 4 & 12 & 6 & 4 & $:::$ \\
\hline$r_{5}$ & 5 & 13 & 5 & 5 & 13 & 5 & 5 & 13 & 5 & 5 & $:::$ \\
\hline$r_{6}$ & 6 & 12 & 4 & 6 & 12 & 4 & 6 & 12 & 4 & 6 & $::::$ \\
\hline$r_{7}$ & 7 & 11 & 3 & 7 & 11 & 3 & 7 & 11 & 3 & 7 & $::::$ \\
\hline$r_{8}$ & 8 & 10 & 2 & 8 & 10 & 2 & 8 & 10 & 2 & 8 & $:::$ \\
\hline
\end{tabular}

In such cases as shown in the above table, the progression gradually progresses to a maximum value and then declines gradually again to its initial minimum value, and then increases again, repeating the cycle. This sort of progression is termed Continuous Simple Harmonic Progression (cSHP).

5(III).1. To determine the position of given number in continuous simple harmonic progression (cSHP). Let there be a cSHP with 'a' being its first element, ' $d$ ' being the common difference between any two consecutive elements in first ' $k$ ' non-repeated elements and ' $n$ ' be the total number of rows of the RCP. Then for determining the row-column of the number, $\mathrm{N}_{\mathrm{x}}$ in the given $\mathrm{RCP}$, first we determine its position. The subscript ' $\mathrm{x}$ ' in $\mathrm{N}_{\mathrm{x}}$, determines the $(\mathrm{x}-1)$ th repetition of the number $\mathrm{N}$.

Consider the figure:

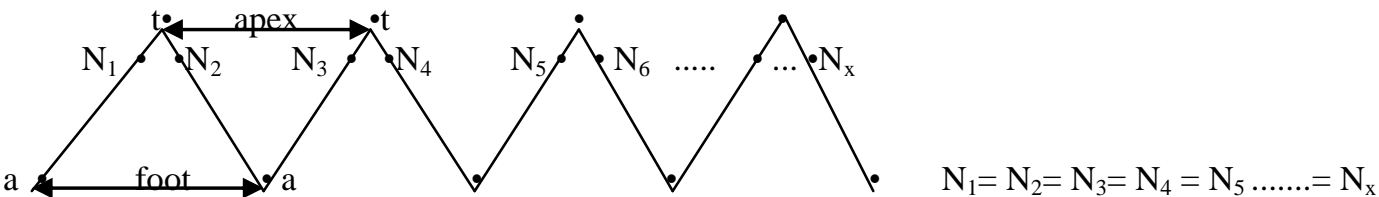

Let ' $\mathrm{t}$ ' be the maximum number reached at the apex, and ' $a$ ' be the minimum number at the foot. It can be easily seen that,

$$
\mathrm{k}=(\mathrm{t}-\mathrm{a}) / \mathrm{d}+1
$$

(i) For determining the position of ' $\mathrm{t}$ ' and ' $\mathrm{a}$ ',

$\mathrm{Pt}_{\mathrm{x}}=2(\mathrm{k}-1)(\mathrm{x}-1)+\mathrm{k}, \quad$ and $\mathrm{Pa}_{\mathrm{x}}=2(\mathrm{k}-1)(\mathrm{x}-1)+1$

(ii). For determining positions of elements, a $<\mathrm{N}_{\mathrm{x}}<\mathrm{t}$

Position of $\mathrm{N}_{1}, \mathrm{p}=\left(\mathrm{N}_{1}-\mathrm{a}\right) / \mathrm{d}+1=\mathrm{k}_{1}$

Now two cases arise.

(a). When ' $\mathrm{x}$ ' is even, $\quad \mathrm{p}_{\mathrm{Nx}}=2(\mathrm{k}-1)(\mathrm{x} / 2-1)+\left(2 \mathrm{k}-\mathrm{k}_{1}\right)=\mathrm{x}(\mathrm{k}-1)+2-\mathrm{k}_{1}$ (b). When ' $\mathrm{x}$ ' is odd, $\quad \mathrm{p}_{\mathrm{Nx}}=2(\mathrm{k}-1)\{(\mathrm{x}+1) / 2-1\}+\mathrm{k}_{1}=(\mathrm{k}-1)(\mathrm{x}-1)+\mathrm{k}_{1}$

Once the position is determined, the row-column position can be determined by the usual method.

5(III).2. For determining the number for a given row- column position 
Let for a given cSHP, as in 1., be all the cases required. If ' $r c$ ' be the row-column position of any number, then its position in a one row progression is given by, $\quad \mathrm{p}=\mathrm{n}(\mathrm{c}-1)+\mathrm{r}$. If ' $\mathrm{k}$ ' be the number of non-repeated elements, then

$$
\mathrm{m}_{1}(\mathrm{k}-1) \leq \mathrm{p}-2<\mathrm{m}_{2}(\mathrm{k}-1)
$$

[where $\mathrm{m}_{1}$ and $\mathrm{m}_{2}$ are the greatest and smallest integer respectively, which satisfies the above equation].For all cases, $m_{2}=m_{1}+1$ Now, two cases arise,

(a). when $\mathrm{m}_{1}$ is even, (increasing cSHP), $\quad \mathrm{p}_{\mathrm{N} 1}=\mathrm{p}-(\mathrm{k}-1) \mathrm{m}_{1}$ (b). when $\mathrm{m}_{1}$ is odd, (decreasing cSHP), $\quad \mathrm{p}_{\mathrm{N} 1}=(\mathrm{k}-1) \mathrm{m}_{2}-(\mathrm{p}-2), \quad$ [where $\mathrm{p}_{\mathrm{N} 1}$ is the position of the number, the first time it appears in cSHP].

The number can be determined as, $\quad \mathrm{N}=\mathrm{a}+\left(\mathrm{p}_{\mathrm{N} 1}-1\right) \mathrm{d}$

If, $\mathrm{a}=1$, and $\mathrm{d}=1$, then, $\mathrm{p}_{\mathrm{N} 1}=\mathrm{N}$

In case (a).when $\mathrm{m}_{1}$ is even, it is observed that the number is a part of the increasing wave which makes an acute angle with the foot (base).

In case (b).when $\mathrm{m}_{1}$ is odd, it is observed that the number is a part of decreasing wave which makes an obtuse angle with the foot.

\section{5(III).3. Frequency of elements in a given column}

$\mathrm{f}_{\mathrm{c}}=($ Total number of rows in column $) /($ total number of distinct elements $)=\mathrm{n} / \mathrm{k}$

5(III).4. Periodicity: It is defined as the total number of columns after the cSHP repeats itself. The period is given by,

(a). $\mathrm{T}=(\mathrm{k}-1) /($ H.C.F. of $(\mathrm{k}-1) \& \mathrm{n}), \quad$ [when, ' $\mathrm{n}$ ' is even], [if ' $\mathrm{k}$ ' is even: refer to generalised equation given below]

(b). $\mathrm{T}=2(\mathrm{k}-1) /($ H.C.F. of $(\mathrm{k}-1) \& \mathrm{n}), \quad$ [when , 'n' is odd]

5(III).5. Frequency of elements in a period

For elements, $a<\mathrm{N}<\mathrm{t}$, [where ' $\mathrm{a}$ ' is the foot element and ' $\mathrm{t}$ ' is the apex element]

$\mathrm{f}_{\mathrm{T}}=\mathrm{n} /[$ H.C.F. of $(\mathrm{k}-1) \& \mathrm{n}], \quad$ [when, ' $\mathrm{n}$ ' is even] , [for even ' $\mathrm{k}$ ', refer to the generalised equation]

$\mathrm{f}_{\mathrm{T}}=2 \mathrm{n} /[$ H.C.F. of $(\mathrm{k}-1) \& \mathrm{n}], \quad$ [when, ' $\mathrm{n}$ ' is odd]

Frequency of apex and foot elements is half of the frequency of the rest of the elements.

Therefore, $\mathrm{f}_{\mathrm{T}} \mathrm{f}_{\mathrm{T}} / 2$

5(III).6. Positions for phase change

These are the positions in which ascending or descending part of a wave changes its direction. Positions of phase change is given by,

$\emptyset=\mathrm{m}(\mathrm{k}-1)+2, \quad$ [where $\mathrm{m}=1,2,3, \ldots \ldots$.

Number of phase changes per period $=f_{T}-1, \quad\left[\right.$ where $f_{T}$ is frequency of element $(a<N<t) N$, in a period].

The foot of a wave is given by, $P_{\text {foot }}=2(\mathrm{~m}-1)(\mathrm{k}-1)+1, \quad$ [where $\left.\mathrm{m}=1,2,3,4, \ldots \ldots ..\right]$

and it represents the beginning of ascending part of the wave.

The apex of a wave is given by, $\quad p_{\text {apex }}=(2 \mathrm{~m}-1)(\mathrm{k}-1)+1, \quad$ [where $\mathrm{m}=1,2,3,4, \ldots \ldots \ldots$. ]

and it represents the beginning of the descending part of the wave.

5(III).7. A generalised equation

5(III).8. (i) Sum of elements of a given column

$$
\begin{aligned}
& 2(\mathrm{t}-\mathrm{a}) / \mathrm{nd}=\mathrm{p} / \mathrm{q}, \quad \text { [simplest ratio] } \\
& \mathrm{p}=\mathrm{T}(\text { period of the cSHP), and } \\
& \mathrm{q}=\mathrm{f}_{\mathrm{T}}^{\prime} \text { (frequency of apex or foot elements) }
\end{aligned}
$$

If ' $n$ ' be the total number of fixed rows in a cSHP, let ' $d$ ' be the c.d., ' $k$ ' be the total number of distinct elements, ' $a$ ' be the first element and ' $c$ ' be the column whose sum is to be determined. We have to first determine if the given column has any position of phase change as given by, $\quad \varnothing=\mathrm{m}(\mathrm{k}-1)+2$,

$[\mathrm{m}=1,2,3, \ldots \ldots$.$] .$

If there is no position of phase change in the column or if there is only one phase change position and that is at the beginning of the column, then the sum of elements is determined as follows: The position of first element of the column is, $\mathrm{p}=\mathrm{n}(\mathrm{c}-1)+1$

The number is determined using the relation,

$(\mathrm{k}-1) \mathrm{m}_{1} \leq \mathrm{p}-2<(\mathrm{k}-1) \mathrm{m}_{2}$

If, $\mathrm{N}$ be the number obtained, then sum of column elements is,

$\mathrm{Sc}=\mathrm{n}[2 \mathrm{~N}-(\mathrm{n}-1) \mathrm{d}] / 2, \quad\left[\right.$ when $\mathrm{m}_{1}$ is odd $]$, and

$\mathrm{Sc}=\mathrm{n}[2 \mathrm{~N}+(\mathrm{n}-1) \mathrm{d}] / 2, \quad\left[\right.$ when $\mathrm{m}_{1}$ is even $]$.

If the given column has a phase change, then we have to determine whether the phase change is due to foot or apex element.

(a). If $x^{\prime}$ th be the row where the foot element is located in the column, then

$\mathrm{Sc}=\mathrm{x}\{2 \mathrm{a}+(\mathrm{n}-1) \mathrm{d}\} / 2+(\mathrm{n}-\mathrm{x})\{2(\mathrm{a}+\mathrm{d})+(\mathrm{n}-\mathrm{x}-1) \mathrm{d}\} / 2, \quad$ [ where ' $\mathrm{a}$ ' is the foot element $]$ 
(b). If $x$ 'th be the row where the apex element is located in the column, then

$\mathrm{Sc}=\mathrm{x}\{2 \mathrm{t}-(\mathrm{x}-1) \mathrm{d}\} / 2+(\mathrm{n}-\mathrm{x})\{2(\mathrm{t}-\mathrm{d})-(\mathrm{n}-\mathrm{x}-1) \mathrm{d}\} / 2, \quad[$ where ' $\mathrm{t}$ ' is the apex element]

This is for one phase change. For two or more phase changes, the sum of elements can be similarly be determined.

(ii). As the columns get repeated after ' $\mathrm{T}$ ', so

$\mathrm{Sc}_{\mathrm{i}}=\mathrm{S}\left(\mathrm{T}+\mathrm{c}_{\mathrm{i}}\right)=\mathrm{S}\left(2 \mathrm{~T}+\mathrm{c}_{\mathrm{i}}\right)=\mathrm{S}\left(3 \mathrm{~T}+\mathrm{c}_{\mathrm{i}}\right)=$

[ where $\mathrm{Sc}_{\mathrm{i}}$ is the sum of elements of the $\mathrm{c}_{\mathrm{i}}$ th column]

(iii). When ' $n$ ' is odd, $(n+1) / 2$ represents the middle row of the $c S H P$. Let $c_{1}$ be the column in which the foot element is present in the $(\mathrm{n}+1) / 2$ th row for a given period and $\mathrm{c}_{2}$ be the column in which the apex element is present in the $(n+1) / 2$ th row of the same period.

Position of the foot element is given by, $\quad \mathrm{p}_{\text {foot }}=2(\mathrm{~m}-1)(\mathrm{k}-1)+1, \quad[$ where $, \quad \mathrm{m}=1,2,3, \ldots .$.

Position of any element in middle row is, $\quad \mathrm{p}=\mathrm{n}\left(\mathrm{c}_{\mathrm{i}}-1\right)+(\mathrm{n}+1) / 2$

Since the foot element lies in the middle row, so

$$
2(\mathrm{~m}-1)(\mathrm{k}-1)+1=\mathrm{n}\left(\mathrm{c}_{\mathrm{i}}-1\right)+(\mathrm{n}+1) / 2
$$

Solving, we get, $\quad c_{1}=[4(m-1)(k-1)+(n+1)] / 2 n$

The value of ' $\mathrm{m}$ ' should be so adjusted so that $\mathrm{c}_{1}$ turns out to be an integer. The first value of ' $\mathrm{m}$ ' for which

$\mathrm{c}_{1(1)}$ turns to be an integer gives the foot to be in the first period; 2 nd value of ' $\mathrm{m}$ ', gives the foot to be in the $2 \mathrm{nd}$ period and is equal to the integral value of $\mathrm{c}_{1(2)}$, and so on.

Similarly the position of column of apex element in the middle row is given by,

$$
\mathrm{c}_{2}=[2(2 \mathrm{~m}-1)(\mathrm{k}-1)+(\mathrm{n}+1)] / 2 \mathrm{n}
$$

Now, it is observed that, $\mathrm{Sc}_{1}$ (sum of elements in the column where the foot element is present in middle row) is minimum in the period and the corresponding $\mathrm{Sc}_{2}$ (sum of elements where the apex element is present in the middle row) is maximum in the period.

The sum of elements of column equidistant from $\mathrm{Sc}_{1}$ is equal, and similar is the case with $\mathrm{Sc}_{2}$, provided the column shouldn't extend beyond the period.

\section{5(III).9. Sum of elements in a given row in a given period}

Let ' $n$ ' be the total number of fixed rows in a cSHP, let ' $d$ ' be the c.d., ' $k$ ' be the total number of distinct elements, and ' $a$ ' be the first element. Then sum of elements for any period is given as, (i) when ' $n$ ' is odd, $\mathrm{S}_{\text {row } 1}=\mathrm{S}_{\text {row } 2}=\mathrm{S}_{\text {row } 3}=\ldots \ldots \ldots \ldots \ldots . . . .=\mathrm{S}_{\text {row } \mathrm{n}}=[\{(\mathrm{k}+1)(\mathrm{k}-1) \mathrm{d}\}+\{2(\mathrm{a}-\mathrm{d})(\mathrm{k}-1)\}] /\{$ H.C.F. of $(\mathrm{k}-1) \& \mathrm{n}\}$

(ii) when ' $n$ ' is even

(a). and $\mathrm{T}$ is even,

$\mathrm{S}_{\text {row } 1}=\mathrm{S}_{\text {row } 2}=\mathrm{S}_{\text {row } 3}=\ldots \ldots \ldots \ldots \ldots . . . .=\mathrm{S}_{\text {row } \mathrm{n}}=[\{(\mathrm{k}+1)(\mathrm{k}-1) \mathrm{d}\}+\{2(\mathrm{a}-\mathrm{d})(\mathrm{k}-1)\}] /\{$ H.C.F. of $(\mathrm{k}-1) \& \mathrm{n}\}$

(b).and $\mathrm{T}$ is odd, and ' $\mathrm{k}$ ' is even and, $\mathrm{T}=(\mathrm{k}-1)$, [i.e. H.C.F. of $(\mathrm{k}-1) \& \mathrm{n}=1$ ]

$\mathrm{S}_{\text {row } 1}=\mathrm{S}_{\text {row } 3}=\mathrm{S}_{\text {row } 5}=\ldots \ldots \ldots \ldots . . . . . . . \mathrm{S}_{\text {row }(2 \mathrm{n}-1)}=\left(\mathrm{k}^{2}-2\right) \mathrm{d} / 2+(\mathrm{a}-\mathrm{d})(\mathrm{k}-1)$

$\mathrm{S}_{\text {row } 2}=\mathrm{S}_{\text {row } 4}=\mathrm{S}_{\text {row } 6}=\ldots \ldots \ldots \ldots \ldots=\mathrm{S}_{\text {row } 2 \mathrm{n}}=\mathrm{k}^{2} \mathrm{~d} / 2+(\mathrm{a}-\mathrm{d})(\mathrm{k}-1)$

(c). and $\mathrm{T}$ is odd, and ' $\mathrm{k}$ ' is odd or when H.C.F. of $(\mathrm{k}-1) \& \mathrm{n} \neq 1$

It is observed that if the sum of the elements in 1 st row be ' $\mathrm{x}$ ', then the sum of elements in the next row is $(\mathrm{x}+$ d). Further the sum of elements themselves forms a sort of cSHP with total number of distinct elements equal to $(h+1)$, where ' $h$ ' is the H.C.F. of ' $n$ ' and $(k-1)$. This is similar to the situation as discussed under discontinuous Simple Harmonic Progression-( point 8).

The sum of elements in the 1 st row is given by,

$\mathrm{Sr}_{1}=\left[(\mathrm{k}+1)(\mathrm{k}-1) \mathrm{f}_{\mathrm{T}}^{\prime} / \mathrm{n}-\mathrm{h} / 2\right] \mathrm{d}+(\mathrm{a}-\mathrm{d}) \mathrm{T}$

The sum of elements of other rows can be determined simply by following the cSHP with ' $\mathrm{k}$ ' equal to $(\mathrm{h}+1)$ and common difference equal to 'd'.

5(III).10. Principle of Reversibility: For any cSHP, the arrangement of elements in 2nd row is reverse of the arrangement in the last row in a given period, and the same procedure is followed by, 3rd row and ( $\mathrm{n}-1)$ th row, 4th row and ( $\mathrm{n}-2)$ th row and so on.

The cSHP having ' $n$ ' odd has only the first row which does not have its reverse(reflection) in a period, whereas cSHP having ' $n$ ' even, has two rows ( 1 st and $(n / 2+1)$ th row) which do not have reverse (reflection).

Note $\rightarrow$ Similarly, there is continuous Complex Harmonic Progression in which the apex element increases with each cycle of the progression. This is not included in this paper.

\section{Row Column Height Progression (HP)}

Consider an array as shown below:

(Height) $\mathrm{H}_{1}$

\begin{tabular}{|l|l|l|l|l|l|l|l|l|}
\hline Row/column & $\mathrm{C}_{1}$ & $\mathrm{C}_{2}$ & $\mathrm{C}_{3}$ & $\mathrm{C}_{4}$ & $\mathrm{C}_{5}$ & $\mathrm{C}_{6}$ & $\mathrm{C}_{7}$ & $\mathrm{C}_{8}$ \\
\hline $\mathrm{R}_{1}$ & 1 & 2 & 3 & 4 & 5 & 6 & 7 \\
\hline $\mathrm{R}_{2}$ & 9 & 10 & 11 & 12 & 13 & 14 & 15 \\
\hline $\mathrm{R}_{3}$ & 17 & 18 & 19 & 20 & 21 & 22 & 16 \\
\hline $\mathrm{R}_{4}$ & 25 & 26 & 27 & 28 & 29 & 30 & 23 & 31 \\
\hline
\end{tabular}




\begin{tabular}{|c|c|c|c|c|c|c|c|c|}
\hline \multicolumn{9}{|c|}{ (Height) $\mathbf{H}_{2}$} \\
\hline Row/column & $\mathrm{C}_{1}$ & $\mathrm{C}_{2}$ & $\mathrm{C}_{3}$ & $\mathrm{C}_{4}$ & $\mathrm{C}_{5}$ & $\mathrm{C}_{6}$ & $\mathrm{C}_{7}$ & $\mathrm{C}_{8}$ \\
\hline $\mathrm{R}_{1}$ & 33 & 34 & 35 & 36 & 37 & 38 & 39 & 40 \\
\hline $\mathrm{R}_{2}$ & 41 & 42 & 43 & 44 & 45 & 46 & 47 & 48 \\
\hline $\mathrm{R}_{3}$ & 49 & 50 & 51 & 52 & 53 & 54 & 55 & 56 \\
\hline $\mathrm{R}_{4}$ & 57 & 58 & 59 & 60 & 61 & 62 & 63 & 64 \\
\hline \multicolumn{9}{|c|}{$\left(\right.$ Height) $\mathrm{H}_{3}$} \\
\hline Row/column & $\mathrm{C}_{1}$ & $\mathrm{C}_{2}$ & $\mathrm{C}_{3}$ & $\mathrm{C}_{4}$ & $\mathrm{C}_{5}$ & $\mathrm{C}_{6}$ & $\mathrm{C}_{7}$ & $\mathrm{C}_{8}$ \\
\hline $\mathrm{R}_{1}$ & 65 & 66 & 67 & 68 & 69 & 70 & 71 & 72 \\
\hline $\mathrm{R}_{2}$ & 73 & 74 & 75 & 76 & 77 & 78 & 79 & 80 \\
\hline $\mathrm{R}_{3}$ & 81 & 82 & 83 & 84 & 85 & 86 & 87 & 88 \\
\hline $\mathrm{R}_{4}$ & 89 & 90 & 91 & 92 & 93 & 94 & 95 & 96 \\
\hline
\end{tabular}

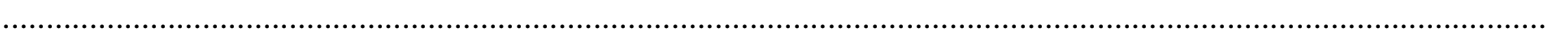

In this sort of array progression, the row and column are fixed but the numbers increases progressively with increasing height. The best example to illustrate this in the practical world is the 3-dimensional arrangement of a multi-storeyed building in which the room numbers are arranged in progression from the ground floor to the top floor.

Let the total number of rows be ' $\mathrm{R}$ ' and total number of columns be ' $\mathrm{C}$ ' for any fixed-row-column height progression (HP), having ' $a$ ' as the first element and ' $d$ ' being the common difference between any two successive elements.

6.1. Suppose we have to find a number, $N$ in the 'r'th' row, 'c'th' column and ' $h$ 'th' height, then

(a).When the progression is in the direction of the row, that is, it is a fixed-column Row-Height Progression (rHP), $\quad \mathrm{N}=\mathrm{a}+[\mathrm{RC}(\mathrm{h}-1)+\mathrm{C}(\mathrm{r}-1)+\mathrm{c}-1] \mathrm{d}$

(b). When the progression is in the direction of the column, that is, it is a fixed-row Column-Height Progression (cHP), $\quad \mathrm{N}=\mathrm{a}+[\mathrm{RC}(\mathrm{h}-1)+\mathrm{R}(\mathrm{c}-1)+\mathrm{r}-1] \mathrm{d}$

6.2. For determining the row-column-height $(\mathrm{RCH})$ of a number, $\mathrm{N}$ in a fixed-row column Height Progression (cHP)

Let the row, column, height $(\mathrm{RCH})$ of $\mathrm{N}$ be' rch'. Then,

(i). When $\mathrm{RCd}$ is a factor of $(\mathrm{N}-\mathrm{a}+\mathrm{d})$, then

(a) Height, $\mathrm{h}=\frac{N-a+d}{R C d}$, row, $\mathrm{r}=\mathrm{R}$, and column, $\mathrm{c}=\mathrm{C}$

(ii). When $\mathrm{RCd}$ is not a factor of $(\mathrm{N}-\mathrm{a}+\mathrm{d})$

(a). Height, $\mathrm{h}=\left\lfloor\frac{N-a+d}{R C d}\right\rfloor$, [smallest integer function mode], or

alternatively, $\frac{N-a+d}{R C d}=\mathrm{h}_{0} \frac{l}{m}$, (simplest ratio). Height, $\mathrm{h}=\mathrm{h}_{0}+1$

(b). For determining the column, we first find the fractional part of height, ' $\mathrm{h}$ '.

$$
\mathrm{h}=\mathrm{p} \frac{q}{R C d}, \quad[\text { where, } \mathrm{p} R C d+q=\mathrm{N}-\mathrm{a}+\mathrm{d}]
$$

Column, $\quad \mathrm{c}=\left\lfloor\frac{q}{R C d} \times \mathrm{C}\right\rfloor=\left\lfloor\mathrm{F}_{\mathrm{c}} \times \mathrm{C}\right\rfloor, \quad\left[\right.$ where, $\left.\mathrm{F}_{\mathrm{c}}=\frac{q}{R C d}\right]$, or

alternatively, $\quad \frac{l}{m} \times \mathrm{C}=\mathrm{c}_{0} \frac{l 0}{m 0}$, (simplest ratio). Column, $\mathrm{c}=\mathrm{c}_{0}+1$

(c). and for determining the row, we first determine the fractional part of column, ' $c$ ',

$\mathrm{c}=\mathrm{p}_{0} \frac{\mathrm{q} 0}{R d}$, [where, $\left.\mathrm{p}_{0} \mathrm{Rd}+\mathrm{q}_{0}=\mathrm{q}\right]$

row, $\quad \mathrm{r}=\frac{q 0}{R d} \times \mathrm{R}=\frac{q 0}{d}$, or

alternatively, row, $\mathrm{r}=\frac{l 0}{m 0} \times \mathrm{R}$

\subsection{For determining the row-column-height of sum of numbers in cHP}

Let there be ' $p$ ' numbers whose row-column-height be designated as, $r_{1} c_{1} h_{1}, r_{2} c_{2} h_{2}, r_{3} c_{3} h, \ldots \ldots . ., r_{p} c_{p} h_{p}$. Then for determining the row-column-height of the sum of numbers $\mathrm{S}$, designated as ' ${ }^{x} c_{x} h_{x}$ '

$\mathrm{RCH}$ of $\mathrm{S}\left(\mathrm{r}_{\mathrm{x}} \mathrm{c}_{\mathrm{x}} \mathrm{h}_{\mathrm{x}}\right)=\mathrm{r}_{1} \mathrm{c}_{1} \mathrm{~h}_{1}+\mathrm{r}_{2} \mathrm{c}_{2} \mathrm{~h}_{2}+\mathrm{r}_{3} \mathrm{c}_{3}+\ldots \ldots \ldots \ldots .+\mathrm{r}_{\mathrm{p}} \mathrm{c}_{\mathrm{p}} \mathrm{h}_{\mathrm{p}}$ row, $\mathrm{r}_{\mathrm{x}}=\mathrm{r}_{1}+\mathrm{r}_{2}+\mathrm{r}_{3}+\ldots \ldots \ldots \ldots+\mathrm{r}_{\mathrm{p}}-a \mathrm{R} \leq \mathrm{R}, \quad\left[\right.$ where, $a \in \mathrm{I}$, and $\mathrm{r}_{\mathrm{x}}>0$ ]

Let, $\mathrm{c}_{0}=\mathrm{c}_{1}+\mathrm{c}_{2}+\mathrm{c}_{3}+\ldots \ldots \ldots \ldots+\mathrm{c}_{\mathrm{p}}+\mathrm{C}\left[\mathrm{h}_{1}+\mathrm{h}_{2}+\mathrm{h}_{3}+\ldots \ldots \ldots+\mathrm{h}_{\mathrm{p}}-\mathrm{p}\right]-[\mathrm{p}-(\mathrm{a}+1)]$

then, column, $\mathrm{c}_{\mathrm{x}}=\mathrm{c}_{0}-b \mathrm{C} \leq \mathrm{C}$, [where, $\mathrm{b} \in \mathrm{I}$, and $\mathrm{c}_{\mathrm{x}}>0$ ]

and, height, $\left.\mathrm{h}_{\mathrm{x}}=\mid \mathrm{c}_{0} / \mathrm{C}\right\rfloor$, [smallest integer function mode]

6.4. For determining row-column-height after subtraction between two numbers in cHP

Let there be two numbers whose row-column-height be designated as $r_{2} c_{2} h_{2}$ and $r_{1} c_{1} h_{1}$. Then the row-column-

height of their difference, $D\left(r_{x} c_{x} h_{x}\right)=r_{2} c_{2} h_{2}-r_{1} c_{1} h_{1}$, is defined when

$\mathrm{h}_{2}>\mathrm{h}_{1}$, or when, $\mathrm{h}_{2}=\mathrm{h}_{1}$ and, $\mathrm{c}_{2}>\mathrm{c}_{1}$, or when $\mathrm{h}_{2}=\mathrm{h}_{1}, \mathrm{c}_{2}=\mathrm{c}_{1}$, and $\mathrm{r}_{2}>\mathrm{r}_{1}$

(i). When, $\mathrm{c}_{2}>\mathrm{c}_{1}$

(a). $\mathrm{r}_{\mathrm{x}} \mathrm{c}_{\mathrm{x}} \mathrm{h}_{\mathrm{x}}=\left(\mathrm{r}_{2}-\mathrm{r}_{1}\right)\left(\mathrm{c}_{2}-\mathrm{c}_{1}+1\right)\left(\mathrm{h}_{2}-\mathrm{h}_{1}+1\right)$, when, $\mathrm{r}_{2}>\mathrm{r}_{1}$ 
(b). $\quad r_{x} c_{x} h_{x}=\left(r_{2}+R-r_{1}\right)\left(c_{2}-c_{1}\right)\left(h_{2}-h_{1}+1\right)$, when, $r_{2} \leq r_{1}$, [where, $R$ is the total number of rows]

(ii). When, $\mathrm{c}_{2} \leq \mathrm{c}_{1}$

(a). $r_{x} c_{x} h_{x}=\left(r_{2}-r_{1}\right)\left(c_{2}+C-c_{1}\right)\left(h_{2}-h_{1}\right)$, when, $r_{2}>r_{1}$, [where, $C$ is the total number of columns]

(b). $r_{x} c_{x} h_{x}=\left(r_{2}+R-r_{1}\right)\left(c_{2}+C-c_{1}\right)\left(h_{2}-h_{1}\right)$, when, $r_{2} \leq r_{1}$

Similarly, multiple operations can be carried out in row-column-height progression. The basics are similar as to the row and column progression. Therefore I leave it to the readers to determine the other operations, and other forms of progression like fixed-height-column row progression, fixed-height-row column progression, continuous and discontinuous forms of simple and complex harmonic height progression, etc .

\section{Application of Row Column \& Height Progression Theory}

1. A man reads a 210 paged novel. The time taken by him to read a page varies linearly with difference of 1 minute but discontinuously, with $1 \mathrm{~min}$. being the minimum and $7 \mathrm{~min}$. being the maximum. Find the time taken by him to read 2 nd page, 7 th page, 12 th page, 147th page.

Solution. The given problem is a sort of discontinuous Simple Harmonic Progression (dSHP). Period of dSHP as arranged as such is :

$\begin{array}{lllllll}1 & 6 & 4 & 2 & 7 & 5 & 3 \\ 2 & 7 & 5 & 3 & 1 & 6 & 4 \\ 3 & 1 & 6 & 4 & 2 & 7 & 5 \\ 4 & 2 & 7 & 5 & 3 & 1 & 6 \\ 5 & 3 & 1 & 6 & 4 & 2 & 7\end{array}$

Period, $\quad \mathrm{T}=\frac{k}{\text { HCF of } k \text { \& } n}=7 / 1=7$

Number of periods up to $147=147 /(7 \times 5)=21 / 5=4 \frac{1}{5}$

Therefore, $\mathrm{n}(\mathrm{T})=4$, and two terms further, $29 \frac{2}{5}$,

Therefore, $\mathrm{S}(4 \mathrm{~T})=4 \times \mathrm{k}[2 \mathrm{a}+(\mathrm{k}-1) \mathrm{d}] / 2=4 \times 7[2+6] / 2=112$

Therefore, time taken by the man to read up to 147 th page along the sequence is, $112+2+7=121 \mathrm{~min}$.

\section{Conclusion}

The row-column-height progression is a modification of sequence and series in algebraic number theory. The numbers dealt in this paper are natural numbers, and therefore this progression theory can find a wide usage in number theory to solve a wide list of conjectures. The array arrangement of numbers can have applications in computers, and can be utilised for other practical purposes. This is not the end, but the beginning of an end. From hence, further research can be done in this field of number theory as there are many arrays in the complex harmonic progression which haven't been discussed in this paper, and therefore will be a lesson for students.

[1]. As it is a direct conjecture, so there are no references.

\section{References}

